\title{
Meniscus tear surgery and meniscus replacement
}

\author{
Javier Vaquero ${ }^{1}$ \\ Francisco Forriol ${ }^{2}$ \\ 1 Hospital Universitario Gregorio Marañon, Madrid, \\ Spain \\ 2 Department of Clínica Sciences, University San \\ Pablo - CEU, Boadilla del Monte, Spain
}

Corresponding author:

Francisco Forriol

Department of Clínica Sciences, University San

Pablo - CEU

Campus Montepríncipe

28668 Boadilla del Monte, Spain

E-mail: fforriol@mac.com

\section{Summary}

Objective: the menisci are easily injured and difficult to repair. The aim of this study was to analyze the current state of meniscal surgery aimed at preserving morphology and conserving the biomechanics of the knee to prevent joint degeneration.

Methodology: a search of the electronic medical literature database Medline was conducted, from http://www.ncbi.nIm.nih.gov/pubmed. The search was not limited by language. Candidate articles were identified by searching for those that included the keywords meniscus, surgery, suture, implant, allograft. The limits were included for clinical research and clinical trials. Basic research was not included. The studies selected were evaluated and classified in three different categories: basic science, reconstruction (suture and meniscectomy) and implants (scaffolds and allograft).

Results: the consequences of meniscectomy performed at a young age can lead to a joint cartilage degeneration twenty years later. There are few surgical options for the repair of meniscal injuries in order both to preserve the meniscus and to ensure the long term survival of the knee joint, meniscectomy, repair, suturing the tear, or reconstruction, when a meniscal allograft or synthetic substitute is used to replace the meniscus, but the biomechanical properties of the native meniscus are not reproduced entirely by the scaffolds that exist today.
Conclusion: therapies that successfully repair or replace the meniscus are therefore likely to prevent or delay osteoarthritis progression.

KEY WORDS: knee, meniscus, allograft, suture, scaffolds.

\section{Introduction}

The menisci play an important role in maintaining healthy articular cartilage. The knee meniscus is a functional structure, which protects the articular cartilage by both increasing the joint congruity and contact area, and preventing the focal concentration of stresses ${ }^{1}$. Three areas can be distinguished in the meniscus, the area in which the meniscus joins the capsule, the vascular area (red) and the avascular area (white), which are important when it comes to determining the indications and taking decisions with regard to repair. On the other hand, the meniscus is partly covered by the synovial, without forming part of it, and synovial cells could play an important role in healing, because they may differentiate producing pluripotential cells ${ }^{2,3}$.

The menisci are also easily injured and difficult to repair. An injury to the medial or lateral meniscus is often found in asymptomatic individuals, and even more frequent in osteoarthritis (OA) patients. Meniscus injuries have been associated with early onset of $\mathrm{OA}$, and meniscectomy is often followed by signs of $\mathrm{OA}^{4,5}$. New vessel formation from preexisting capillaries is essential for repairing the damaged tissues and experimental studies have provided a different perspective on avascular area lesions ${ }^{6}$ suggesting that this part of the meniscus is unlikely to heal. The mechanisms of meniscal repair follow two patterns ${ }^{7,8}$ : the extrinsic pathway, which is usually used in lesions of the vascular area where there is a network of capillaries, which supply undifferentiated mesenchymal cells with nutrients to induce healing (Fig. 1), and the intrinsic pathway, which is based on the self-repair capacity of the meniscal fibrocartilage and the synovial fluid. The more central the location of the meniscus injury, the lower the intrinsic responsiveness is. On the other hand, the origin of the repair cells is uncertain, but the presence of fibroblasts in the meniscal injury at an early stage suggests that the superficial meniscal cells and the synovial cells have an important role as a source of stem cells in the joint ${ }^{8-11}$. Knee arthroscopy is the gold standard in diagnosis 

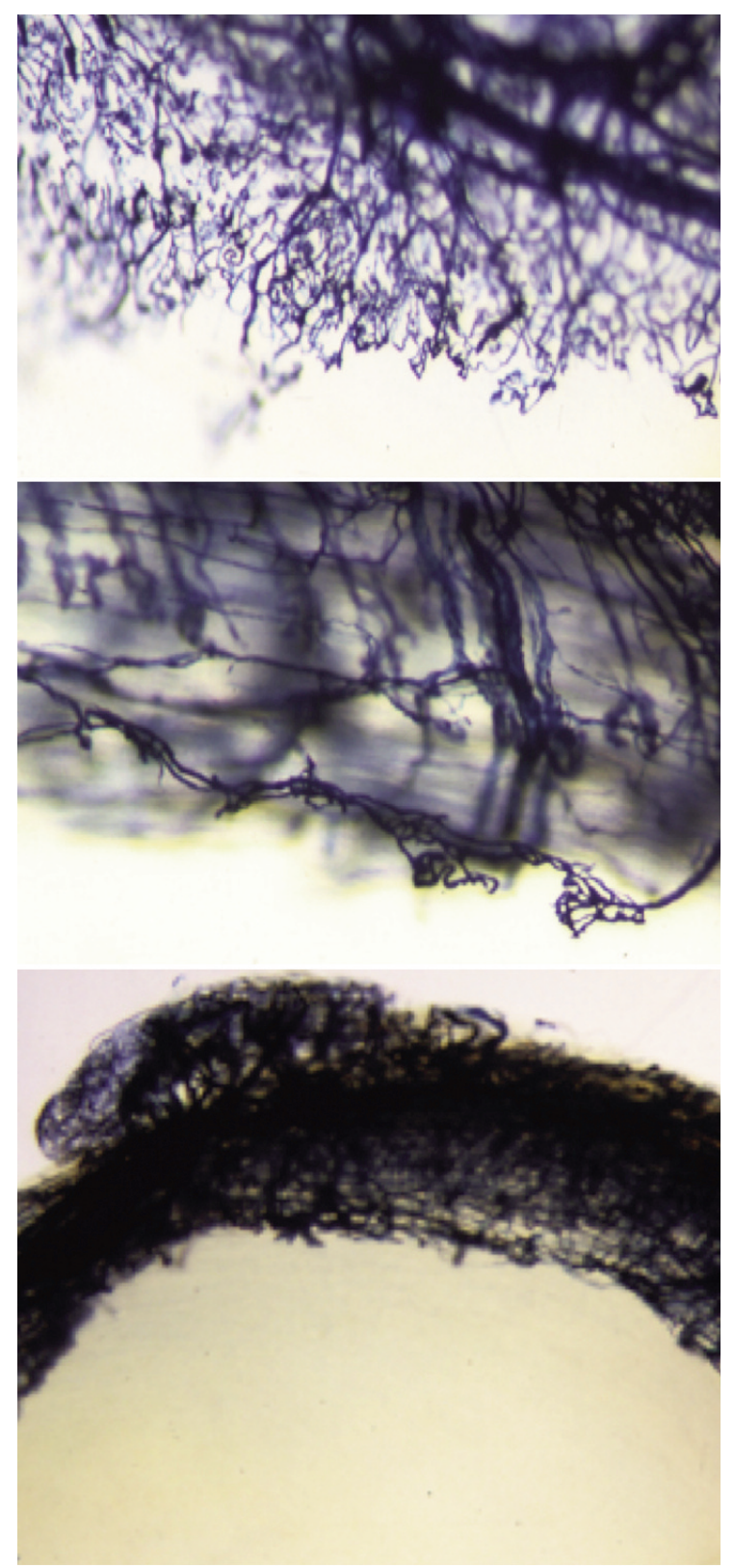

Figure 1. Sheep meniscus, vessels border between the red and the white area (Spaltenholz technique).

and simultaneous treatment of meniscus disorders. But most patients undergo magnetic resonance imaging (MRI) before arthroscopy, although MRI results are not always consistent with arthroscopic findings ${ }^{12}$. Chambers et al. ${ }^{13}$ compared the MRI meniscal images with arthroscopy, finding that MRI scanning was $90.5 \%$ sensitive, $89.5 \%$ specific and $90.1 \%$ accurate. Roßbach et al. ${ }^{14}$ found sensitivity/specificity of $58 / 93 \%$ for anterior horn, $94 / 46 \%$ for posterior horn of medial meniscus and $71 / 81 \%$ for anterior and $62 / 82 \%$ for posterior horn of lateral meniscus. The specificity of conventional MRI can be improved by employing at least two T2-weighted sequences, but this still leaves a shortfall in sensitivity and if MRI is contraindicated, computed tomography arthrography seems a promising alternative.

A search of the electronic medical literature database Medline was conducted, from http://www.ncbi.nIm. nih.gov/pubmed. The search was not limited by language. Candidate articles were identified by searching for those that included the keywords meniscus, surgery, suture, implant, allograft. The limits were included for clinical research and clinical trials. Basic research was not included. The studies selected were evaluated and classified in three different categories: basic science, reconstruction (suture and meniscectomy) and implants (scaffolds and allograft). We follow the ethical standards of the Muscles, Ligaments and Tendon Journal ${ }^{15}$.

The aim of this study was to analyze the current state of meniscal surgery aimed at preserving morphology and conserving the biomechanics of the knee to prevent joint degeneration.

\section{Indications for meniscal repair}

The young, active patient with a meniscal tear poses a significant challenge for the surgeon ${ }^{16}$. Important patient characteristics include age, cartilage status, concomitant anterior cruciate ligament $(A C L)$ reconstruction, and compliance. Important features of the tear included location, morphology, acuity, and stability (Fig. 2). The MOON Cohort study ${ }^{17}$ concluded that $30 \%$ of medial meniscal tears and $10 \%$ of lateral meniscal tears are eligible for all-biological repair; $35 \%$ of medial meniscal tears and $35 \%$ of lateral meniscal tears are eligible for an advanced repair technique; and $35 \%$ of medial meniscal tears and $55 \%$ of lateral meniscal tears are eligible for scaffold replacement.

Conservative techniques such as debridement and trephination, have not proven their clinical efficacy. Meniscal debridement is therefore used for degenerative tears that are not amenable to repair ${ }^{10,18}$ (Fig. 3). In cases of meniscal tear, it is necessary to consider whether it is possible to repair it, whether it may heal, and whether, once it has been repaired, the meniscus will recover its mechanical function ${ }^{8}$. At present it is accepted that longitudinal tears of the vascular periphery must be repaired, because they heal in most cases. However, meniscal repair in the avascular area is dubious, and it is not known whether the mechanical function of the meniscus will be preserved. Beaufils et al., ${ }^{19}$ established that meniscal repair should only be used to heal peripheral meniscal lesions affecting healthy meniscal tissue in vascularized areas (red-red zone or red-white zone). Traumatic meniscal lesions do not always require a meniscectomy; no surgery or meniscal repair should be considered as a matter of course. The assessment and management of non-traumatic degenerative meniscal lesions depend on the extent of cartilage damage. But on many occasions the indication is to do nothing, above all in asymptomatic cases and in stable meniscal injuries in 

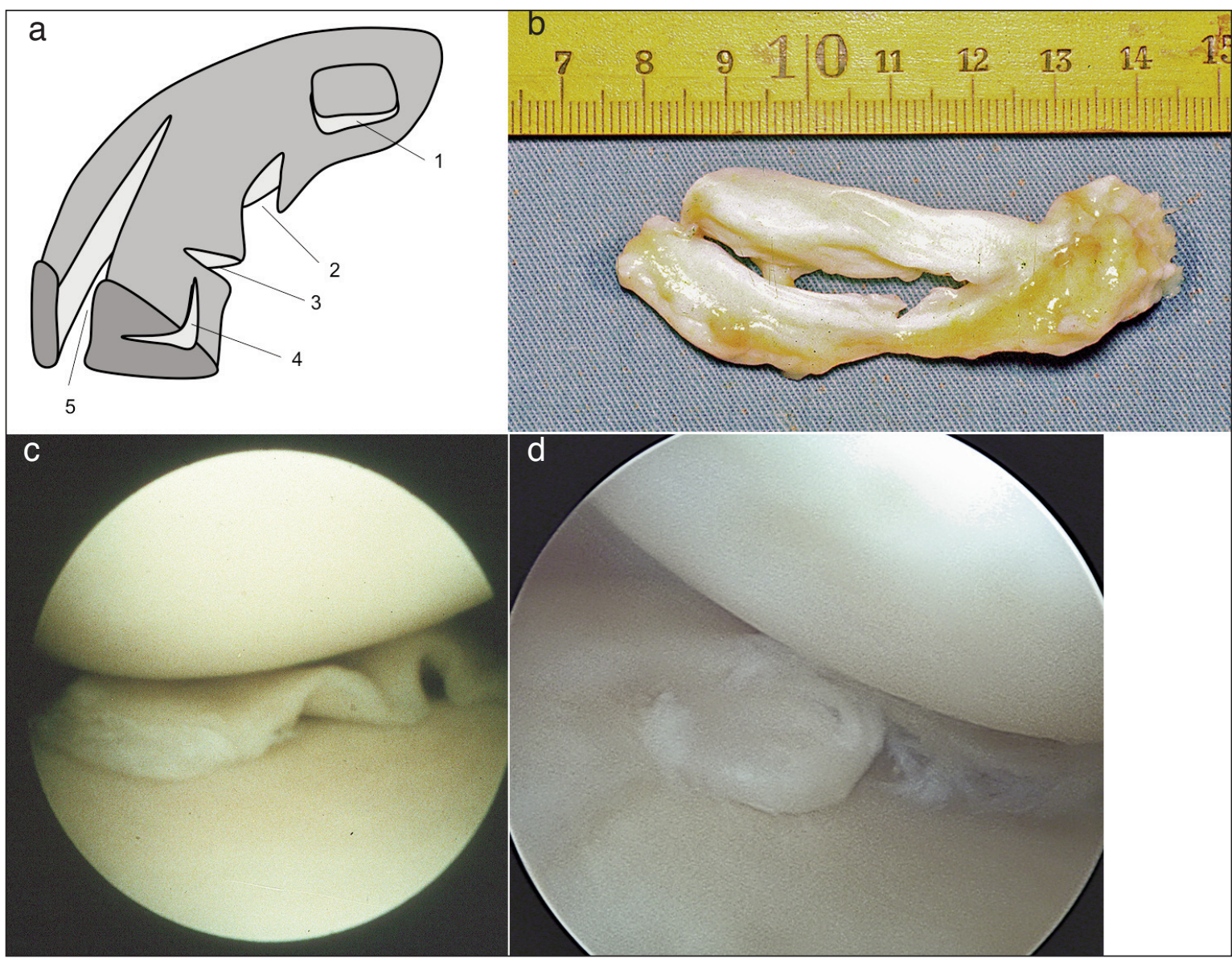

Figure 2. a) Different types of meniscal tears: 1. horizontal, 2. vertical flap, 3. radial tear, 4. horizontal tear, 5. longitudinal tear; b) longitudinal tear; c) meniscus torn; d) meniscus pearl.

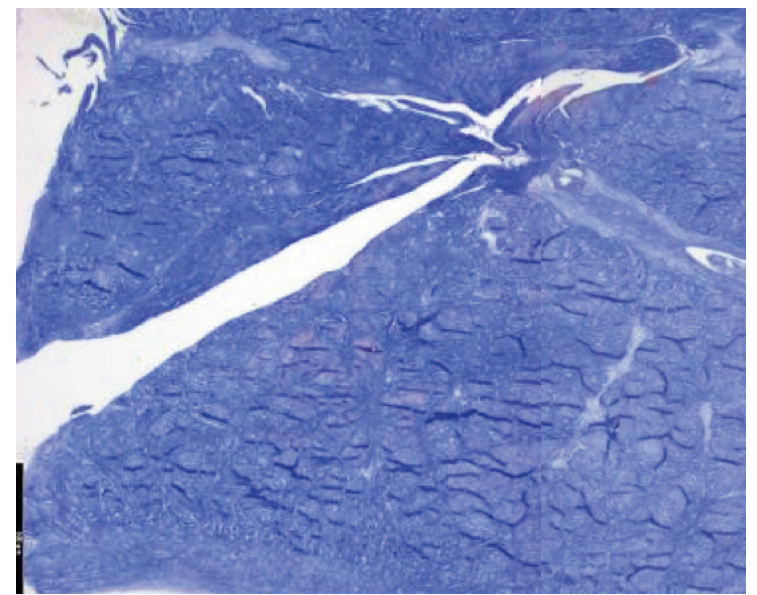

Figure 3. Experimental trephination in sheep meniscus: 4 months post-op without repair signs.

unstable knees that are going to undergo repair. Longitudinal tears less than one centimeter in length may heal spontaneously and if the meniscal tear is partial, its stability should be assessed and treatment need not be given. Surgery is also not indicated in in- juries measuring less than one centimeter or in incomplete tears in the peripheral vascularized areas ${ }^{20}$. Surgery can also be avoided in asymptomatic knees in people with a low level of physical activity ${ }^{21}$ or in asymptomatic degenerative lesions ${ }^{22}$. Repair of a meniscal lesion should be considered carefully if the tear is peripheral and longitudinal, with concurrent anterior cruciate ligament reconstruction, and in younger patients ${ }^{23}$.

Radial meniscal tears have historically been treated by partial meniscectomy, although they are more degenerative than longitudinal tears. Repair of complete radial meniscal tears is the key to restoring the mechanical integrity necessary to maintain hoop tension in the meniscus. Partial meniscectomy is reserved for symptomatic injuries in stable knees, when the lesion is in an area where repair is not possible and the individual is active ${ }^{24}$. D'Lima et al. ${ }^{25}$ concluded that after total meniscectomy, the femoral contact area decreased by $26 \%$ with a concomitant increase in average contact stresses (36\%) and peak contact stresses $(33 \%)$. This means that indications for meniscectomy decrease in comparison to other repair techniques because repair techniques are mechanically superior to partial meniscectomy ${ }^{26}$. Noyes and Barber-West- 
in ${ }^{27}$ recommend the preservation of meniscal tissue wherever possible in athletically active patients regardless of age, basing indications for the procedure on current and future activity levels. It should not be forgotten that a "repairable" meniscal injury in which the ACL is ruptured is less likely to heal and much more likely to tear again 28-30.

Meniscal repair is performed exclusively on younger populations, while older populations are subject to partial meniscectomy procedures ${ }^{13}$. Resection techniques have major limitations, because removal of the tissue in the area of the external meniscus may lead to alterations of the geometry of the meniscal section and thereby affect its functioning ${ }^{9}$.

Meniscal repair, with sutures or implants, and meniscal replacement, with meniscal allografts or scaffolds, have become usual in order both to preserve the meniscus and to ensure the long term survival of the knee joint. There are few surgical options for the repair of meniscal injuries. These include total or partial meniscectomy; repair, suturing the edges of the lesion together, or reconstruction, when a meniscal substitute is used to replace a segment of missing meniscus. Meniscal repair is a priority after the instability has been corrected, in peripheral lesions and in young, very active patients. The most successful repairs are usually in younger patients who have an acute, vertical tear in the vascular portion of the meniscus ${ }^{10}$, where repairs are often performed in order to decrease the chance of the patient developing $\mathrm{OA}^{12,31,32}$.

The decision as to whether to perform meniscectomy or repair must be made on an individual basis, and the characteristics of both patient and tear should be taken into consideration.

\section{Meniscal suture techniques and their biomechani- cal considerations}

Vertical suture techniques are superior to horizontally placed sutures and \#2-0 to \#1 sutures are recommended for suture repair. Barret et al. ${ }^{33}$, recommend the use of permanent sutures, as reabsorbable sutures do not ensure the stabilization of a meniscus which, after 12 weeks, though largely healed, still does not have the capacity to withstand certain types of activity. Vertical sutures hold circumferential fibers better because they encircle them like a rope holding a bunch of tree branches. In the same way, horizontal sutures hold radial fibers better. The vertical suture configuration created by the all-inside technique has been found to result in lower displacement, higher load to failure, and greater stiffness compared with the horizontal inside-out technique ${ }^{34}$ but there was little difference in biomechanical properties between vertical and horizontal repair ${ }^{35}$. If a horizontal suture is used in meniscal repair, the most suitable larger diameter suture should be used ${ }^{36}$. Repair of radial meniscal tears with a second suture and a shorter distance from the meniscal rim has a positive influence on primary stability ${ }^{37}$. The superior biomechanical meniscal repair fixation provided by capturing greater tissue volume may enable safe earlier participation in functional exercise activities ${ }^{36}$.

Currently, arthroscopic meniscal repair procedures include the inside-out, the outside-in and the all-inside technique. Inside-out and outside-in repairs requires an incision to allow for needle capture, knot tying and protection and identification of the neurovascular structures. Today, the all-inside technique is preferred - even though it is arthroscopically more complicated, it means that external incisions are not necessary and there is little risk of damaging the neurovascular structures. Most commercially available devices for all-inside meniscal repair using ultrahighmolecular-weight polyethylene suture provide fixation comparable to the classic vertical mattress suture repair technique in human cadaveric meniscus ${ }^{38}$. The inside-out repair remains the gold standard ${ }^{39}$ and is the most appropriate for a bucket-handle type tear of the medial or lateral meniscus ${ }^{40}$. All-inside arthroscopic meniscal repairs are favored by most clinicians because of their lower complication rate and decreased morbidity compared with inside-out techniques. Choi et al. ${ }^{41}$ found no difference in meniscal healing between inside-out and all-inside repair techniques in combination with $\mathrm{ACL}$ reconstructions. The all-inside technique has gained in popularity recently and has outcomes that approach those of the insideout repair with decreased morbidity but increased cost. The choice of this technique is most appropriate for small tears requiring few sutures in their repair; outside-in repair can also be employed and is preferred for anterior horn tears ${ }^{40}$ (Fig. 4). Third-generation devices introduced the idea of rigid, bioabsorbable materials; unfortunately, these demonstrated higher failure and complication rates compared with other repair techniques. They were also limited in their ability to adjust compression and tension across the repair. Now, fourth-generation devices have been developed that are flexible, suture-based, and allow for variable compression and retensioning across the tear 39,42 . These have decreased the operating time and the level of surgical skill required 23 .

These devices, which may be shaped like arrows,

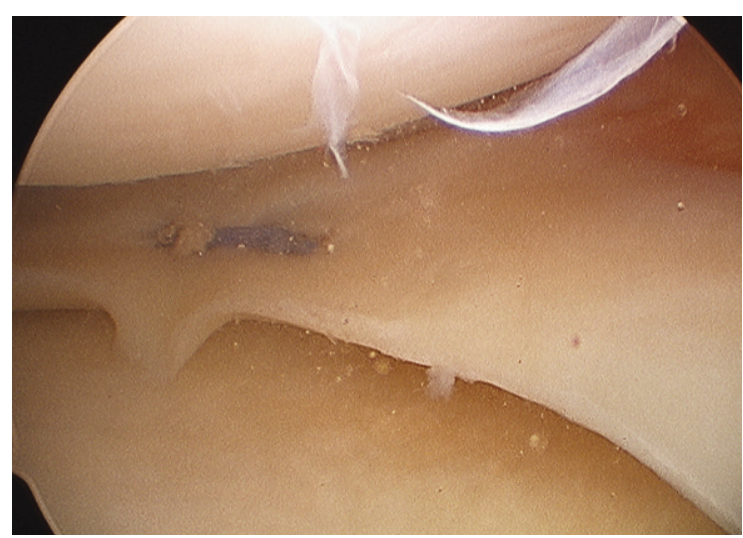

Figure 4. Sutured meniscus. 
screws or stitches ${ }^{43,44}$, reduce the surgical time, simplify the technique and reduce the risk of neurovascular lesions, although it has also been shown that there may be a reaction to the introduction of a foreign body, and they may damage the cartilage, become displaced in the joint 45,46 . This has led to the creation of a second generation of devices, which are more flexible, aimed at achieving a balance between the suture and rigid anchoring systems. A combination of suture techniques and implants might be a treatment option in posterior meniscal lesions ${ }^{10}$. The inside-out repair with all-inside meniscal devices shows comparable biomechanical properties compared with inside-out suture repair in cyclic loading 47 . However, meniscal repair constructs are also exposed to shear forces parallel to the circumferential meniscal fibers during healing, particularly in the midportion of the meniscus (Fig. 5).

The changes that the different materials undergo over time also have an important impact on the time that elapses before the meniscal tissue is capable of receiving and absorbing all the stresses. Barber et al. ${ }^{48}$ studied the behavior of different types of suture in the synovial fluid. Polyester (Mersilene $\left.{ }^{\circledR}\right)$ maintains $100 \%$ tension six weeks after implantation; PDS (Polidioxanona $\left.{ }^{\circledR}\right), 40 \%$ after six weeks, which indicates a loss of tension in the third week after insertion; LTS (Policaprolactona ${ }^{\circledR}$ ) presented a slow reduction in tension, maintaining $90 \%$ of its resistance to tear 18 weeks after insertion. Polylactic acids (Vicryl $\left.{ }^{\circledR}\right)$ and polyglycolic acids (Dexon $\left.{ }^{\circledR}\right)$, such as catgut, maintained some of their strength after 3 weeks. Polyglyconate (Maxon $\AA)$ had no significant stiffness after 6 weeks. It is therefore not surprising that they conclude by recommending non-reabsorbable sutures, as the meniscal repair process requires considerable time. Moreover, monofilament non-reabsorbable sutures do less damage to the meniscus and joint tissues $^{49}$. Nitinol can be elongated and become soft and flexible for proper suturing at low temperature. At body temperature, it can contract to its original length, providing stronger knots. Lamprakis et al. ${ }^{50}$ compare this with ethibond $\triangle$ and nylon and show the superior load-to-failure and tensile strength characteristics of nitinol. However, in terms of stiffness and gap resistance force, the results were equivalent to

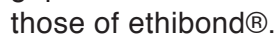

Suture techniques exhibited biomechanical superiority over biodegradable flexible and rigid anchor devices for meniscus repair ${ }^{51,52}$. Becker et al. ${ }^{53}$ pointed out that all the degradable implants they analyzed had lower resistance to tension than sutures did, which suggests that such implants should be inserted very close together, and that in large injuries they should be combined with sutures. Walsh et al. ${ }^{54}$ also analyzed the behavior of a meniscal arrow and stitch
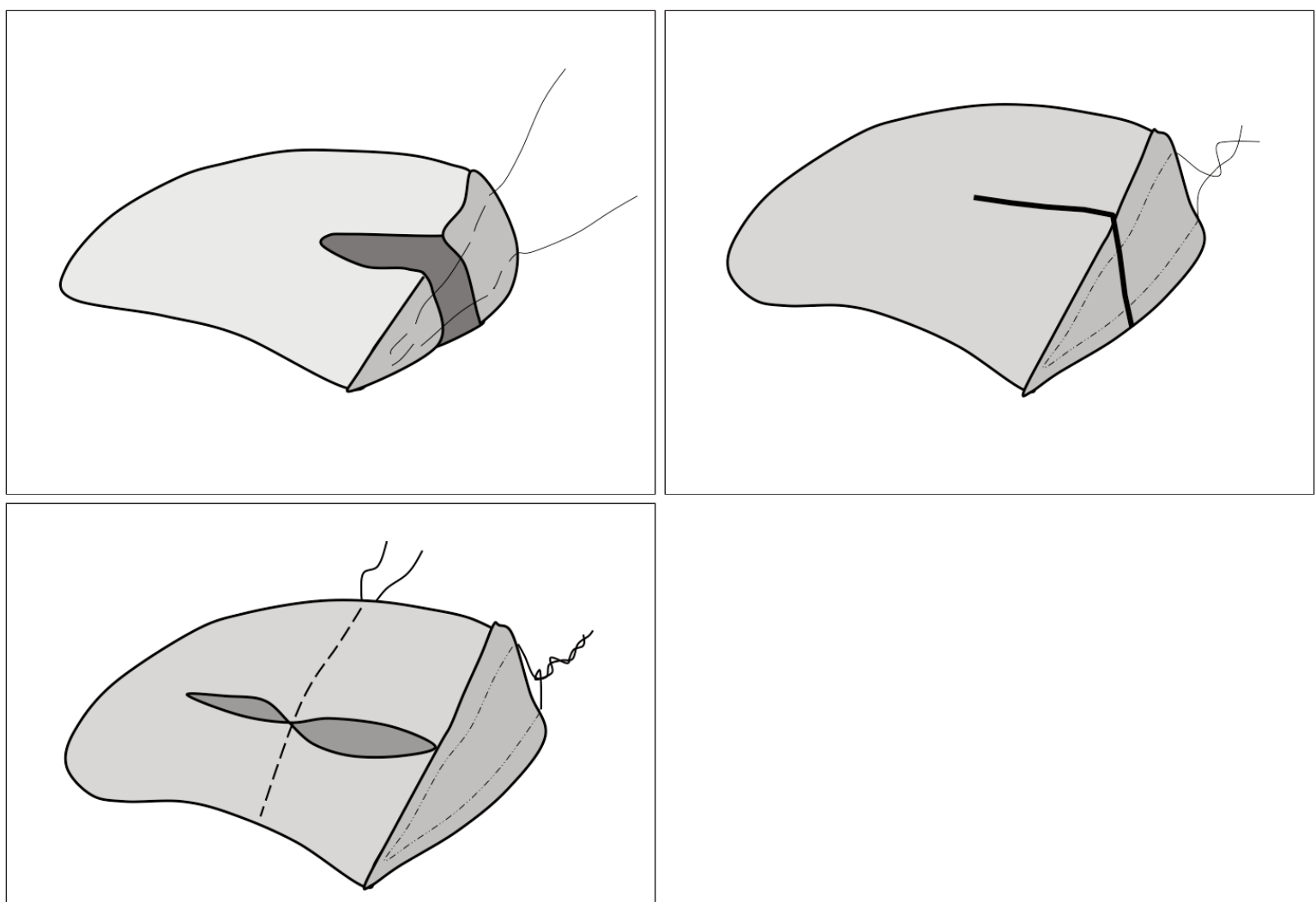

Figure 5. Sutures should mantained the tear edges in contact during the hoop stresses. 
with vertical and horizontal sutures, and observed that the stitch bore less mean tension than the other methods. The stiffness of the majority of flexible meniscal repair implants in a shear condition is markedly reduced 55 .

\section{Techniques associated with sutures to stimulate meniscal repair}

Since meniscal lesions often fail to heal and are hard to repair, meniscal sutures have been used in combination with techniques for stimulating meniscal repair, although most of this work is still at the experimental stage. Dutton et al. ${ }^{56}$ showed that meniscal tears treated with MSCs (Mesenchymal Stem Cells) together with a conventional suturing technique improved healing, but that the mechanical properties of the healed menisci decreased in comparison with the control. Intraarticular injections of allogeneic synovial MSCs appeared to promote meniscus regeneration in a porcine massive meniscal defect model ${ }^{57,58}$.

Arnoczky et al., ${ }^{59}$ knowing the important role played by the hematoma in the initial healing phase of any injury, applied a fibrin clot in a meniscal defect in the avascular area of dogs, which provides a scaffold rich in platelet derived growth factors (PDGF) and fibronectin, to enhance chemotaxis and mitogenic stimuli to the healing cells. The fibrin clot seems to guide the intrinsic meniscal response to heal, as a scaffold and as a source of stimulating factors. Van Trommel et al. ${ }^{60}$ treated five complete radial external meniscal lesions, in the avascular popliteal portion, using a fibrin clot. Three years later, the follow-up arthroscopy and MRI testified that the lesions had healed. Piontek et al. ${ }^{61}$ suggested treating meniscal tears by suturing and wrapping them in collagen matrix, followed by injection of liquid bone marrow collected from the tibial proximal epiphysis, into the area of meniscal lesion. Ra et al. ${ }^{62}$ treated complete radial tears of the meniscus using arthroscopic inside-out repair with fibrin clots, and their results showed good meniscal healing and excellent clinical outcomes. Kamimura et al. ${ }^{63}$ proposed exogenous fibrin clots to repair horizontal cleavage tears of the meniscus.

The problem of the application of the fibrin clot is its poor adhesive property: it cannot stimulate healing if it does not remain fixed and stable. Cyanoacrylate-type glues are biodegradable, bacteriostatic, hemostatic adhesives that have been used experimentally in many tissues, particularly the skin. The elasticity of such glues allows them to adapt to meniscal mobility during knee movements. Fibrin glue is a combination of coagulation factors (fibrinogen, thrombin, $\mathrm{CaCl} 2$ and FactorXIII) with aprotinin. The adhesive properties of the fibrin glue are superior to the clot but it lacks the biological properties, and can overlap the edges of the injury without stimulating the repair process ${ }^{64}$. It has also been shown that the association of fibrin glue and bone marrow MSCs promoted meniscal healing, as did the combination of fibrin glue and VEGF65. Fibrin glue can be used in combination with a suture ${ }^{66}$, or be fragmented and applied with a syringe $\mathrm{e}^{8,67}$.
The synovial membrane holds the synovium-derived stem cells (SDSCs). Jo et al. ${ }^{68}$ distinguished between the peripheral synovial cells and the non-peripheral cells: the synovial area has a mixed cell population with round cells (macrophage type) and fusiform cells (fibroblast type). The SDSCs have an unknown function in meniscal repair but have a high differentiation rate and serve as a rich source of stem cells, and are sensitive to the stimuli of different growth factors with greater chondrogenic than osteogenic capacity2,69-71. In vitro, the synovial graft showed a higher cell proliferation and collagen neoformation ${ }^{72}$ and stimulated the fibroblast derived growth factors, which had an important effect on the expression of type II collagen ${ }^{73}$.

The transplantation of the synovium to the avascular area of the meniscus plays an important role in the repopulation of the meniscus injury. Cisa et al. ${ }^{74}$ published good results in rabbits after using synovial flaps. Kobuna et al. ${ }^{75}$ using microangiography in dogs, demonstrated that vessels located on the femoral surface and the inner part of the meniscus reached the sutured area after 6 weeks, and showed healing with a fibrovascular tissue. However, Shirakura et al. ${ }^{76}$ in dogs, found new capillaries from the periphery that failed to reach the lesion, and in their study repair was not achieved.

\section{Clinical results of meniscal suture}

The need to prevent post-meniscectomy syndrome has driven the development of meniscal repair. Ikeuchi ${ }^{77}$ performed the first arthroscopic meniscal suture, and DeHaven ${ }^{78}$ described and performed the first techniques for repairing the meniscus through open surgery. Henning et al. ${ }^{79}$ described the possibilities of arthroscopic meniscal surgery, and then reached the conclusion that it was better to repair peripheral injuries by conventional surgery, whereas lesions to the central area of the meniscus, which were harder to reach, should be approached by arthroscopy. DeHaven et al. ${ }^{80}$ sutured lesions $2 \mathrm{~mm}$ from the capsule and obtained repairs in $85 \%$ of cases. Of his nine failures, six were associated with instability of the ligaments. In the earliest published studies ${ }^{81}$, the differences were established between meniscal repair of an isolated injury and that of lesions associated with ligamentoplasty, which yielded better results ${ }^{82}$. This was due to the fact that traumatic injury to the meniscus is often found in menisci that are structurally normal, and which have a blood supply to the hemarthrosis, through the rupture of blood vessels ${ }^{83}$.

Although size does not influence the likelihood of repair 81,84 , it has been shown that bucket-handle injuries longer than $40 \mathrm{~mm}$ have a higher failure rate than smaller ones. Better results are obtained in recent injuries. Tengrootenhuysen et al. ${ }^{85}$ obtained better results in meniscal repairs performed within 6 weeks of injury $(83 \%)$ than late repairs $(52 \%)$, as meniscal tears tend to become deformated over time ${ }^{79,86,87}$. Worse outcomes have been observed in young patients, perhaps because they take less care in the postope- 
rative period, and in elderly patients, where the meniscus had already degenerated 88,89 .

In the most recent publications, the results are better, but poor results are still to be found in 10 to $20 \%$ of cases in most studies ${ }^{23,90}$. In some of these publications, an arthroscopic second look was used to assess the quality of the repair. Rubman and Noyes ${ }^{91}$, carried out 91 arthroscopic follow-up studies, and found that $25 \%$ of cases could be regarded as healed, $38 \%$ as partially healed, and $36 \%$ as failures. Of the cases in which healing was partial, 54\% required a partial excision, while the others remained stable. Of the failures, $61 \%$ were given a partial meniscectomy, $30 \%$ a second repair operation, and $9 \%$ resection with allograft.

In the opinion of Eggli et al. ${ }^{92}$ an edge more than 3 $\mathrm{mm}$ from the meniscal periphery is a negative prognostic factor. The prognosis and outcome of meniscal injuries are better when they are in the external meniscus, and when they are smalle or acute injuries. Moreover, they should be treated with a non-reabsorbable suture.

Meniscal tears often occur in association with ACL lesions or in chronically unstable knees. The menisci are critical secondary stabilizers of the ACL. ACL reconstruction effectively restores an increased anterior tibial translation in the ACL-deficient knee 93,94 and patients with associated ACL injury had a better chance of a successful outcome, but this was only significant when the ACL was reconstructed at the time of repair ${ }^{85}$. Martinez Albornoz and Forriol95 showed that the concentration of anabolic growth factors was significantly higher in the joint fluid of patients with ACL reconstructed knee than in the meniscectomy group. In concrete, PDGF can play an important role enhancing the healing response of meniscus suture, and can be one of the biological reasons for the higher meniscus healing rate in $A C L$ reconstructed $\mathrm{knee}^{96}$. But meniscus has a limited healing capacity confined to the vascularized periphery, and therefore surgical repair of the avascular regions is not always feasible. The vascularized region and synovial contain MSC which contribute to meniscal regeneration ${ }^{97}$.

\section{A special case of meniscal repair: meniscus pos- terior horn repair}

A meniscus root tear is an avulsion of the tibial insertion of the meniscus or a radial tear close to the meniscal insertion. Meniscal root injuries can compromise knee function and lead to early degenerative changes if not appropriately treated ${ }^{98}$. Clinical diagnosis is difficult, but MRI usually make it possible to identify the lesion. Three different direct MRI signs have been described: radial linear defect in the axial plane, vertical linear defect (truncation sign) in the coronal plane, and the so-called ghost meniscus sign in the sagittal plane, a large radial tear that has completely transected the meniscus. Meniscal extrusion is also considered to be an indirect sign of a root tear but is less common in lateral99,100.
In long chronic ACL insufficiency, Mariani ${ }^{101}$ identified an abnormal movement of the posterior medial meniscal horn, probably due to insufficiency of the posteromedial meniscotibial ligament. Internal rotation of the femur increases the resultant tension substantially, whereas external rotation has the opposite effect ${ }^{23}$.

When the lesion is located in the vascularized zone of the meniscus, management is preferentially arthroscopic $^{102}$, and suturing the horns has been found to increase contact area and reduce peak contact stresses $^{25}$. Meniscal root repair is commonly practised using transtibial pull-out sutures ${ }^{103}$, but the all-inside technique can be used to repair lesions of the posterior horn of the lateral meniscus. However, this technique presents important disadvantages, such as the need for an accessory portal and a high risk of neurovascular damage. Espejo-Baena et al. ${ }^{104}$ proposed an all-inside technique for the posterior horn of the lateral meniscus that takes advantage of the capacious posterolateral recess when the knee is flexed. This technique uses only anteromedial and anterolateral portals with an accessory lateral or transpatellar tendon portal.

Lee et al. ${ }^{105}$ found no between-group difference in 25 patients, with a follow-up of 2 years, where arthroscopic medial meniscus root refixation using the modified Mason-Allen stitch was compared with repair using simple stitches. In a porcine menisci model, Röpke et al. ${ }^{106}$ used a transtibial pull-out suture and found that meniscus root repair was not effective in restoring the normal loading pattern of the cartilage, because cyclic loading caused an elongation of the repair. However, Rosslenbroich et al. ${ }^{107}$, using a transtibial single suture technique, showed significantly higher elongation and lower stiffness and failure load after cyclic loading compared to the health meniscus; a two-suture technique showed no difference in elongation and stiffness but had a lower failure rate.

\section{Complications of meniscal sutures}

Patients with failed meniscal repair have found to have increased radiographic osteoarthritic changes on long-term follow-up compared to patients with successful repair ${ }^{85}$. Current techniques do not require accessory posteromedial or posterolateral incisions and significantly reduce the incidence of complications and pain associated with more invasive surgery. Complications include saphenous and peroneal nerve damage and vascular lesions. The proximity of the posterior horn of the lateral meniscus to the popliteal artery determines the risk of vascular injury on suture. The artery has been found to lie laterally to the midline in $94 \%$ of the cases, with a minimal mean distance from the posterior wall of the lateral meniscus to the popliteal artery of 1 (range: $0.32-1.74) \mathrm{cm}$; this distance is not related to body parameters ${ }^{108}$.

Sohby et al. ${ }^{109}$, in a cadaver study, proposed as an entry point for outside-in repair a point just lateral to the semitendinosus tendon. Baena et al. ${ }^{110}$ indicate 
that when the needle is inserted into the posteromedial region of the knee during inside-out suture, it is far enough from the popliteal neurovascular bundle for the maneuver to be performed with a reasonable safety margin. However, this margin can be increased further still if the needle is inserted into the joint through a point located laterally to the patellar tendon. Cohen et al., ${ }^{111}$ in fresh-frozen cadaver legs, found that the RapidLoc ${ }^{\circledR}$ device seems to be safer, entailing less risk to the popliteal artery than the current FasT-Fix ${ }^{\circledR}$ meniscal repair device. On the other hand, the cannulae used can potentially injure the load transmitting fibers of the meniscus and can cause substantial laceration of the meniscal tissue.

\section{Meniscal reconstruction techniques}

The therapeutic approach to treating meniscal lesions has changed dramatically over the last few years. It is not unusual for surgeons to have to confront situations in which meniscal repair or the limited excision of part of the meniscal tissue is not possible. Now that the consequences of meniscectomy performed in the second, third or fourth decade of life are known, we have become aware that we must seek solutions to replace the meniscus that is extracted and prevent joint deterioration twenty years later ${ }^{4}$. The first reference to meniscal allogenic transplant (MAT), using a free graft, was performed by Milachowski et al. ${ }^{112}$ and, shortly after this, the first lateral meniscus was inserted using arthroscopy ${ }^{113}$. Nevertheless, there has also been considerable interest in synthetic substitutes such as teflon ${ }^{114}$, dacron ${ }^{115}$, silicone, carbon fiber, polymers ${ }^{116}$, SIS (small intestine submucosa) ${ }^{117}$, carbon fibers and polyurethanes or polylactic acid supplements ${ }^{118}$, although to avoid the toxic or carcinogenic effects of such implants some specialists have also proposed mixtures with polycaprolactane and polylactic ${ }^{115}$, but these either produced poor results or are still at an experimental stage. Synthetic materials must fulfill a series of requirements that are hard to meet. They must be compatible materials, with viscoelastic features that protect the cartilage and act to absorb and distribute the joint stresses. Moreover, they also have to integrate into the joint capsule. In the mid-1990s the first results of a collagen implant were published ${ }^{119}$, and recently a polyurethane polymer has completed the experimental stage and gone on the market.

Therapies that successfully repair or replace the meniscus are therefore likely to prevent or delay osteoarthritis progression. The biomechanical properties of the native meniscus are not copied entirely by the scaffolds that exist today. Congruence, fixation, biocompatibility and potential infection will always remain as limitations for the users of allografts.

\section{Synthetic meniscal implants}

There are two scaffold implants designed for meniscal reconstruction or substitution of partial meniscal defects that are currently available in Europe: the Collagen Meniscal Implant (CMI) (Ivy Sports Medicine, Gräfelfing, Germany; Menaflex, ReGen Biologics, Redwood City, CA, USA) and the polyurethane polymer scaffold (PS; Actifit, Orteq Bioengineering, London, United Kingdom). The treatment strategy is similar for the two implants available: upon resection of the damaged tissue the resulting space is filled with a custom-sized, synthetic, porous material, which serves as a scaffold to regenerate meniscus-like tissue. Arthroscopy is used to position the implant, which is then sutured to the remaining native meniscus using horizontal stitches and to the meniscal wall using vertical stitches. The Actifit ${ }^{\circledR}$ implant originally was developed to serve as a full meniscus replacement. Based on the results of a dog study, a partial implant was considered to be a more suitable application since as a total meniscus replacement the implant could not resist the shear forces in the knee joint and cartilage damage could not be prevented ${ }^{116}$. To summarize, the implants available for partial meniscal defects seem to improve clinical scores compared with the pre-operative situation. The use of meniscal scaffolds in the acute setting has not been found to result in improved outcomes in most studies ${ }^{120}$. The results described in the bibliography are good, but the follow-up period is very short, particularly in the case of Actifit ${ }^{\circledR 120-130}$. The mechanical effect of these implants in the long-term has still to be proven.

Advances in scaffold and biomaterial design have evolved not only to guide tissue formation, but also to interact dynamically with and manipulate the wound environment. At present, these efforts are being directed towards strategies that directly address limitations in endogenous wound repair, with the goal of reprogramming the local wound environment from a state that culminates in an inferior tissue repair into a state in which functional regeneration is achieved ${ }^{131}$.

Current indications for use of the CMI include partial meniscus loss with intact rim ant attachments and no grade IV chondral defects ${ }^{132-134}$ in a stable knee. The timing of implantation may either be directly following the meniscectomy or after development of symptoms. The CMI (MENAFLEX. ReGen Biologics, Redwood City, CA, USA) is type 1 bovine achilles tendon collagen, from young animals aged 12 to 18 months, with proteoglycan cross-linked using aldehyde vapor and glycosaminoglycans, hyaluronic acid and condroitin sulphate. In a feasibility study, 8 patients underwent arthroscopic placement of the CMI to reconstruct and restore the irreparably damaged medial meniscus of one knee. Based on measurements, the average amount of meniscus defect before placement of the CMI was $62 \%$, and the average filling of the meniscus defect was $77 \%$ with a range of 40 to $100 \%$. Histological analysis of the CMI-regenerated tissue confirmed new fibrocartilage matrix formation ${ }^{135}$. The CMIregenerated tissue appears similar to the earlier relook arthroscopy, and its appearance is meniscus-like, both grossly and histologically. The average amount of the original defect remaining filled was $69 \%$, with a 
range of 50 to $95 \%$. The positive results of this feasibility study led to a large multicenter randomized (CMI versus meniscectomy alone) clinical trial. A total of 311 partial meniscectomy patients were subdivided into an acute and a chronic injury group and received either the CMI or partial meniscectomy only. After a mean follow-up of five years, it was shown that the $\mathrm{CMI}$ in medial meniscal defects improves clinical outcomes for chronic patients but has no benefits for acute patients ${ }^{119}$.

Zaffagnini et al. ${ }^{136}$ and Monllau et al. ${ }^{137}$ evaluated $\mathrm{CMI}$ at a minimum follow-up of ten years and showed improved functional results for several clinical outcome scores. The studies in which MRI was used to assess the results all show a reduction in the size of the $\mathrm{CMI}$ in the course of the follow-up period and a very different signal intensity to that found in healthy meniscus (Fig. 6).

Verdonk et al. ${ }^{138}$ published the first outcomes of a case series involving 52 partial meniscectomy patients with a follow-up period of 24 months. Statistically significant and clinically relevant pain reduction combined with improved functionality and activity were found from six months post-operatively. In addition, more than $90 \%$ of the patients showed stabilization or improvement of the articular cartilage condition, suggesting the implant's protective effect against cartilage degeneration. However, this study did not include a control group. Spencer et al. ${ }^{139}$ implanted 12 Actifit and 11 Menaflex in 23 patients with post-meniscectomy painful knees and evaluated clinical, radiological and histological results at a mínimum of 1 year folow-up. Scores improved significantly and second-look arthroscopy showed variable amounts of regenerative tissue. There was no progression in chondral wear noted on repeat MRI scanning. However, the $\mathrm{MRI}$ signal from the regenerated tissue in the scaffold did not suggest differentiation into fibrocartilage.

Gelber et al. ${ }^{140}$ determine whether medial meniscal substitution with the Actifit ${ }^{\circledR}$ scaffold improves the outcome of varus knees undergoing open-wedge high tibial osteotomy. Patients with symptomatic varus knees were treated with open-wedge high tibial osteotomies, and the meniscectomy was found to have improved more at short-term follow-up in most of the functional scores evaluated than in those patients with concomitant implantation of a medial Actifit $^{\circledR}$ implant. However, there was no difference in terms of patient satisfaction with the procedure.

\section{Allogenic meniscal transplant}

Meniscal transplantation is generally accepted as an alternative management option for selected symptomatic patients with previous complete or near-complete meniscectomy. The aims of a meniscal replacement are to reduce the pain experienced by some patients following meniscus resection; to prevent the
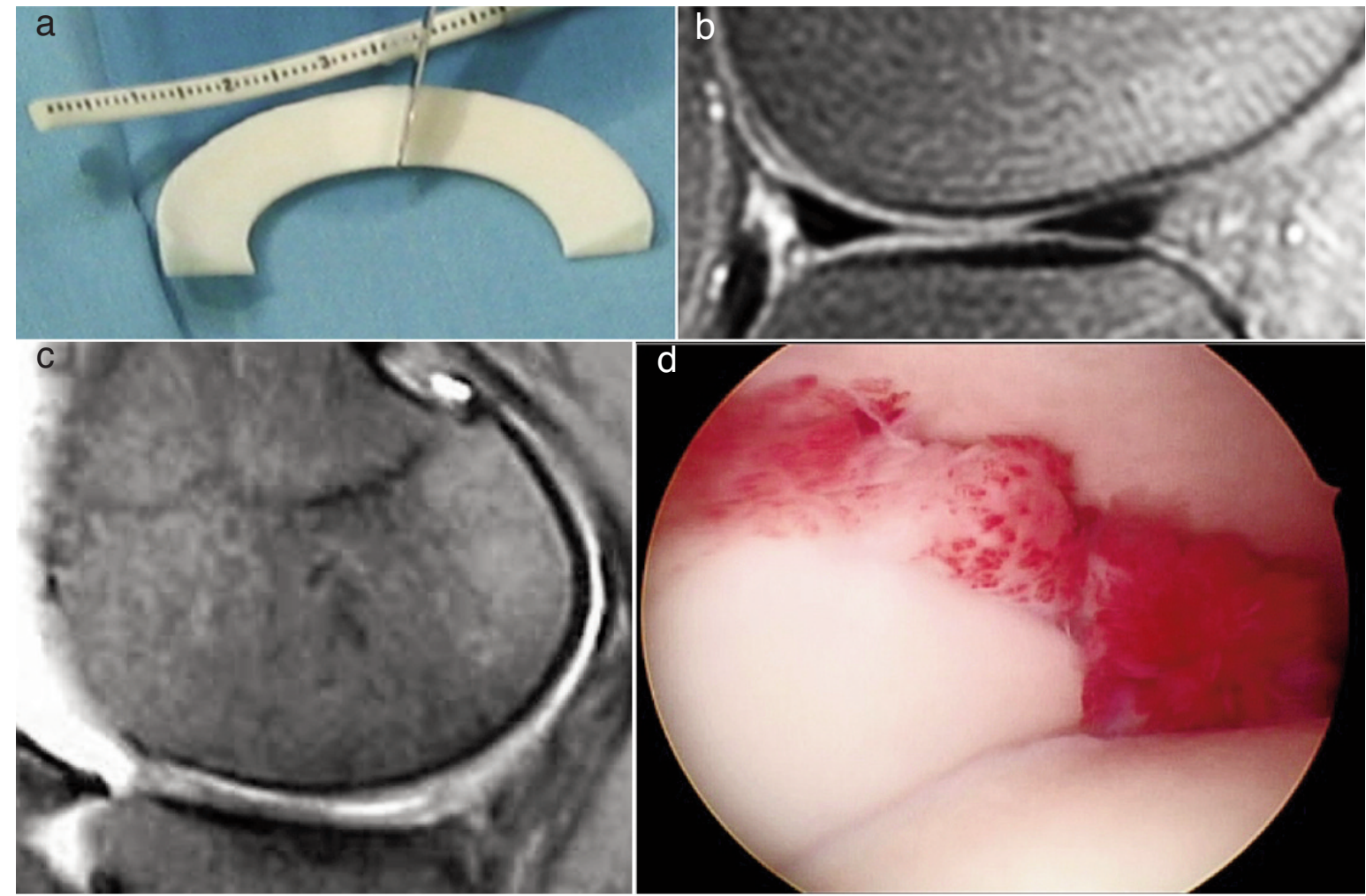

Figure 6. a) Collagen scaffold, b) scaffold 1 year post-op, c) scaffold reabsorbtion, 3 months post-op, d) second-look, scaffold integration with synovium reaction. 
degenerative changes in cartilage and the changes in subchondral bone following meniscus resection; to avoid or reduce the risk of osteoarthritis following meniscus resection; and to restore optimally the mechanical properties of the knee joint after meniscal resection ${ }^{141,142}$.

Two types of meniscal allografts are used for meniscal replacement: fresh and frozen. Lyophilized allografts are no longer performed because of the structural alteration resulting from the use of this conservation technique. Wirth et al. ${ }^{143}$ observed using MRI that the lyophilized allografts shrunk significantly in comparison with native meniscus. Fresh allografts have presented many problems, because they require immune suppression ${ }^{144}$, present a greater risk of transmitting disease, and it has not been demonstrated that viable donor cells remain 4 weeks after transplantation ${ }^{145}$. Frozen allografts are the kind which is used most at present, although there is no evidence that they are capable of protecting the hyaline cartilage in the human knee, or reproducing the meniscal functions (Fig. 7).

The indications for meniscal transplant are strict. The technique may be applied in patients aged under 5055 years, with a stable, well-aligned knee, and with incapacitating pain. The degree of arthrosis present before the operations has a decisive effect on the final result ${ }^{146}$ and this operation is contraindicated in severe osteoarthritis, although not all experts agree. Cameron and Saha ${ }^{147}$ obtained a clear clinical improvement in patients with arthrosis when a meniscal implant was performed, and Stone et al. ${ }^{148}$ found a survival rate of $89.9 \%$ after 4.4 years when they performed 47 MATs in degenerative knees, challenging the contraindications of age and arthrosis severity. Finally, the patient has to be sufficiently motivated to adhere strictly to the postoperative protocol. In patients with instability of the knee and indications for meniscal graft, it is necessary to stabilize the joint by ligament reconstruction prior to transplantation; in the case of malalignment, corrective osteotomy is required $^{10,149}$. Medial meniscal transplantation may also be considered during concomitant anterior cruciate ligament reconstruction, since absence of the medial meniscus results in increased forces in the anterior cruciate ligament graft.

Systemic reactions do not occur, and the grafts can integrate into the joint capsule ${ }^{150}$ (Fig. 8). Rodeo et al. ${ }^{151}$ studied human meniscal allograft transplants, and found that they are repopulated with cells that appear to be derived from the synovial membrane ${ }^{152}$. Although there is histological evidence of an immune response directed against the transplant, this response does not appear to affect the clinical outcome. The presence of histocompatibility antigens on the meniscal surface at the time of transplantation (even after freezing) indicates the potential for an immune response against the transplant. The reason why there is no systemic response seems to lie in the relatively acellular environment of the meniscus and the fact that the few cells present are isolated by an extracellular matrix, which creates a privileged immune state ${ }^{150}$. The comparative studies that have been performed have shown no advantages in maintaining living cells through cryopreservation methods ${ }^{153}$. It is for this reason, rather than on grounds of availability, that frozen menisci have become widely used as grafts in this technique.

On the basis of a literature review, Matava ${ }^{154}$ proposed several principles for surgeons performing this procedure: achieving or reestablishing normal knee alignment and stability; implanting a size-matched, non-irradiated graft with secure fixation of the meniscal horns; and ensuring patients return only to light sports activities to maximize the chances for graft survival. The three prerequisites for a successful meniscal allograft are fixation, graft sizing and precise positioning ${ }^{155}$ and anatomical horn positioning and strong fixation to the bone and capsule of an appropriately sized graft. Patient evaluation should in-

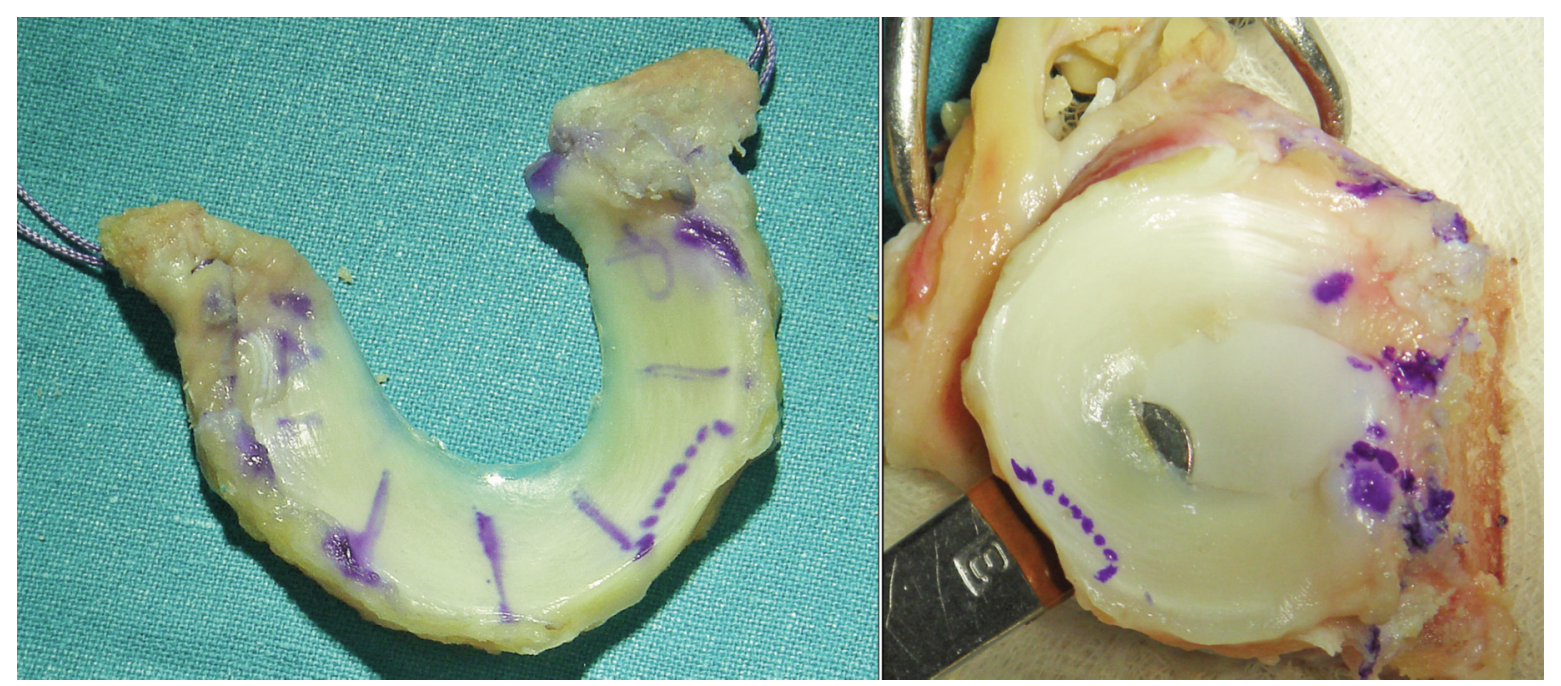

Figure 7. Frozen meniscus allograft with bone blocks before implantation. 


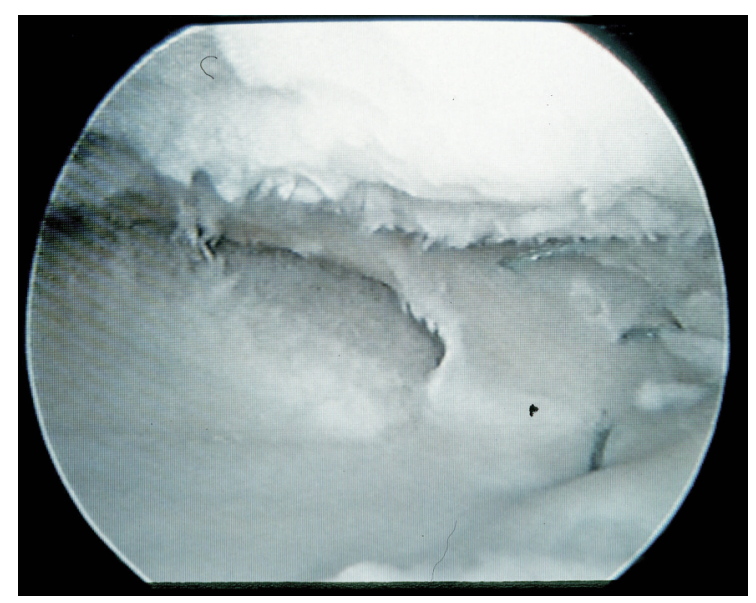

Figure 8. Meniscus allograft presented a good meniscus capsule integration, in a second look 9 months after surgery.

clude standing, leg-long radiographs for assessment of the mechanical axis, and magnetic resonance imaging with appropriate pulse sequences for evaluation of hyaline cartilage thickness. Prophylactic meniscus transplantation after total meniscectomy is not recommended in asymptomatic patients who do not demonstrate articular cartilage deterioration, because predictable long-term success rates are not available ${ }^{156}$.

\section{Technical aspects of meniscal transplant}

Sterilization of allografts is a crucial step in ensuring safety and viability. The current sterilization standards such as $25 \mathrm{kGy}$ and irradiation can have adverse effects on the ultrastructure and biomechanical properties of allograft tissue ${ }^{151,157}$. Lewis et al. ${ }^{158}$ proposed transplantation of meniscal allograft tissue frozen and thawed four times may be compromised in its ability to resist compression, which may undermine its role in replacing native meniscal tissue.

The age of the donor does not appear to affect the initial tensile properties of menisci from donors less than 45 years of age ${ }^{159}$. Gelber et al. ${ }^{160}$ suggest that meniscal cryopreservation does not alter the meniscal ultrastructure or its biomechanical properties, although its cellular viability is highly unpredictable. Gelber et al. ${ }^{161}$ suggest that the freezing process alters the menisci's collagen net. This could partially explain the pathological changes found in shrunken menisci after transplantation (Fig. 9). Moreover, apoptosis also occurs during meniscus cryopreservation $^{162}$

Successful meniscus transplantation depends on an accurate sizing of the meniscal allograft. The radiographic method devised by Pollard et al. ${ }^{163}$ is the current reference standard for meniscus size matching, with a margin of error of about $10 \%$, which is considered tolerable. Jang et al. ${ }^{164}$ analyzed meniscal allograft transplantation in eighteen patients by the conventional Pollard sizing method, reducing the

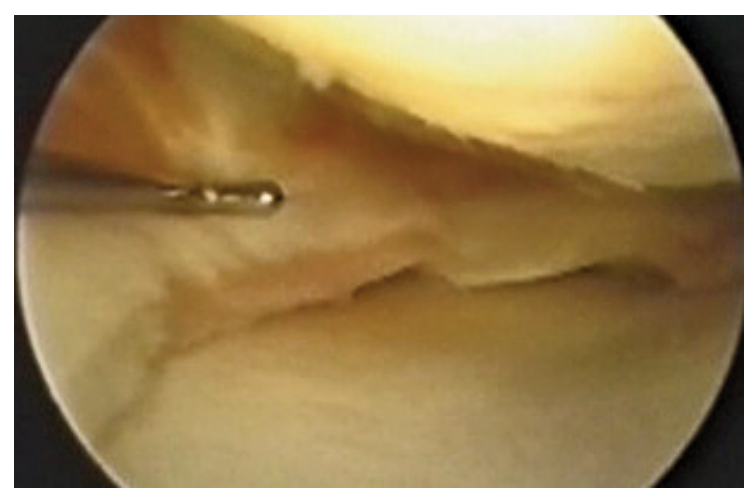

Figure 9. Meniscus shrinkage.

total size of the graft by $5 \%$ from the Pollard method. In meniscus transplantation, allograft size mismatch causes increased contact pressures and early degeneration of the knee. A mismatch on graft selection of less than $10 \%$ of the size of the original meniscus may be acceptable ${ }^{165}$. Accurate sizing and positioning of a meniscal allograft is an important factor for successful outcome of meniscal allograft transplantation. Direct MRI measurement of the contralateral intact meniscus better predicts actual meniscal size than estimation of size indirectly from measurement of the tibial plateau on which it is located. Prodromos et al. ${ }^{166}$ proposed contralateral MRI meniscal measurement as a new gold standard to size menisci before transplantation, but this is problematic for economic and practical reasons. Overall, magnetic resonance imaging proved only slightly more accurate than conventional radiography ${ }^{167}$. Mickiewicz et al. ${ }^{168}$ used X-ray microcomputed tomography to measure the size of the meniscus allograft.

A further aspect of interest in the technique of meniscal allograft is the method for fixing the graft to the joint capsule and tibia. A poorly-anchored meniscus results in excessive mobility and cannot transmit the loads, which damages the joint surfaces ${ }^{169,170}$. The horns of the meniscus are subject to major forces of traction which are three times the body weight ${ }^{171}$ and so their fixation in the transplant has to be extremely firm. Paletta et al. ${ }^{172}$, in his experimental study, showed that section of the meniscal anchors in the area of the horns is equivalent to meniscectomy, and leaves the graft unprotected from the biomechanical point of view. There is some controversy as to what the best system is for achieving resistant fixation. Stone and Rosenberg ${ }^{173}$ published a simple technique for anchoring allografts with sutures, without the need for bone blocks. If the meniscus is not soundly anchored, the same pressures lead to the phenomenon of extrusion towards the joint periphery and we may therefore deduce that in such cases neither the shock forces nor the load can be absorbed properly ${ }^{174}$. Work carried out in the field of finite elements has led to the conclusion that bone blocks should be used to anchor the graft because they meet the need for firm fixation ${ }^{175}$. At present, clinical stu- 
dies also suggest that anchorage in the bone offers better results, whether it is performed with bone blocks or using a the bone slot technique. GonzalezLucena et al. ${ }^{176}$ performed MAT with suture fixation without any bone block and found a high rate of complications (33\%) and revision surgery. Yoldas et al. ${ }^{177}$ examined clinical and patient-reported outcomes following meniscal allograft transplantation with bony fixation performed with bone plugs for medial transplants and using a bone bridge for lateral transplants. No joint space narrowing differences were observed by radiography over time. Abat et al. ${ }^{178}$ compared the functional and radiographic results between horn fixation with or without sutures in 88 meniscal allograft transplants with a mean 5-year follow-up. These two graft fixation methods showed no differences relative to functional and radiographic results but there was a considerably higher rate of complications in transplantations performed with the suture-only technique than those with bony fixation. The choice of using suture alone for the posterior horn meniscal attachment eases the technique of surgery when compared to using a bone plug plus suture, but in the view of Wang et al. ${ }^{179}$, under dynamic loading, transosseous fixation at the meniscal horns provides superior load distribution at the involved knee compartment after meniscal transplantation compared with suture-only fixation.

\section{Results of meniscal transplants}

In a sheep knee study, no radiological differences were observed in the degenerative joint outcome between meniscectomy, meniscus allograft and autograft. All three groups presented signs of osteoarthritis when compared with a healthy control group after 21 months ${ }^{180}$. Meniscal replacement with meniscal allograft provides some protection, albeit incomplete, against joint damage after a meniscectomy ${ }^{181,182}$. The severity of chondral damage in the allograft knees in sheep could not be distinguished from meniscectomized joints ${ }^{183}$. Immediate meniscal transplantation in rabbits has a protective effect on articular cartilage in the long term whereas delayed transplantation leads to even more degenerative changes than meniscectomy alone ${ }^{184}$. Aagaard et al. ${ }^{185}$ examine the gross changes after meniscal allograft transplantation in relation to the articular cartilage changes. For this group, meniscal allograft transplantation reduced degenerative articular cartilage changes within 6 months in sheep knees, but degenerative articular cartilage changes were still present in transplanted knees. Khoshgoftar et al. ${ }^{186}$ indicate that cartilage contact mechanics are more sensitive to implant size than to implant shape.

The available short- and long-term studies of clinical outcomes of MAT are variable and difficult to effectively compare due to the heterogeneity of the study population and the availability of treatment techniques ${ }^{187}$. Meniscal allograft transplantation yields fair to excellent results in almost $85 \%$ of patients; patients report a significant decrease in pain, as well as an increase in activity ${ }^{188-193}$. Meniscal allografts are associated with generally good clinical outcomes, in terms of minimizing radiographic changes, maintaining normal gait and exercise activity and promoting cellular incorporation and tissue healing 150,194. Thijs et al. ${ }^{195}$ show significant improvement of the proprioception of the operated knee at 6 months after surgery compared with the pre-operative condition.

The survival of medial meniscal allografts may improve when reconstruction of the $A C L$ is carried out at the same time as meniscal transplantation in an ACL-deficient knee ${ }^{196}$. Ruef et al. ${ }^{197}$, in patients with concomitant ACL reconstruction, had greater preoperative knee pain levels, but the pain levels at 5 years postoperatively were comparable to those after meniscal repair or partial meniscectomy and ACL reconstruction. Spang et al. ${ }^{198}$ evaluated the effect of meniscectomy and meniscal allograft transplant on ACL and knee biomechanics in 10 human cadaveric knees. Tibial displacement after meniscectomy significantly increased at all flexion ranges and the MAT restored tibial displacement to normal values at 30 and $90^{\circ}$. ACL strain increased significantly after meniscectomy at 60 and $90^{\circ}$ of flexion, and MAT returned the strain values to normal at 60 and $90^{\circ}$.

Combined MAT and cartilage repair or regeneration is a recognized treatment for patients with painful, meniscus injured knees and full-thickness cartilage damage. Harris et al. ${ }^{199}$ analyzed six studies with 110 patients who had undergone combined MAT with cartilage repair or restoration. In 2 studies outcomes of combined surgery were not as good as those of either procedure performed in isolation. Failure occurred in $12 \%$ of patients who underwent combined MAT and cartilage repair, and they required revision surgery. Most failures (85\%) of combined surgery were due to failure of the MAT. Rue et al. ${ }^{200}$ performed simultaneous combined MAT and cartilage restoration procedures in 31 patients with a symptomatic postmeniscectomy knee with a focal chondral defect. MAT offers a safe alternative for those patients. Getgood et al. ${ }^{129}$, in a retrospective review of 48 patients who received simultaneous meniscal and cartilage allograft, found that 10 -year survivorship was $69 \%$ for MAT and $68 \%$ for cartilage repair. In total, $90 \%$ of those responding would have the surgery again and $78 \%$ were either satisfied or extremely satisfied with the outcome.

A MAT associated with high tibial osteotomy resulted in greater improvement at the final follow-up when compared to isolated transplant ${ }^{201}$. In a systematic review, El-Attar et al. ${ }^{202}$ concluded that, although published data are of low evidence level, MAT is safe, reliable and should not be considered experimental. Smith et al. ${ }^{203}$, in a systematic review, evaluated 38 studies with 1,056 allografts, concluded that MAT reduces the progression of osteoarthritis, although it is unlikely to be as effective as the native meniscus. Some long-term follow-up studies showed that the technique resulted in graft degeneration, deformation, and tear, and structural changes in the remodeling process in early meniscus transplantation 
cases, disrupting functional restoration of the original meniscus ${ }^{204}$. In a meta-analysis study, Meredith et al. ${ }^{205}$ indicated that extensive resections and females had the highest correlations with radiographic evidence of OA, and in a follow-up study of 328 unstable knees, the best correlation with the severity of OA was the time that had elapsed since meniscectomy. The most important factor for the allograft incorporation is revascularization, with the migration of vascular knots from the peripheral synovial tissue, which can be obtained with a suitable operative technique and adequate attachment of the meniscus. This is one of the keys to successful transplantation, preventing excessive mobility and the inability to transmit and distribute the loads across the damaged articular surfaces of the joint. Excessive mobility can interrupt revascularization, and in the absence of adequate revascularization, cell death and subsequent matrix disorganization occur 206 .

MAT can present various complications, and a meniscal allograft tear is one of the most common, as are transplant extrusion and shrinkage. Meniscal tears usually occur at the periphery of the meniscal allografts at the capsular junction or the posterior horn, and biomechanical factors, such as high contact stress areas, are a possible causative mechanism. Jung et al. ${ }^{207}$ encountered three unusual cases with multiple radial or horizontal tears, which may possibly have induced by the suture materials used for meniscus allograft fixation.

Shrinkage and size reductions in the area of protected tibial cartilage may be a major problem with freeze dried and fresh frozen grafts ${ }^{150,208}$. Several studies have described shrinkage after MAT; however, no study has specifically quantified the rate or degree of shrinkage that occurs. Carter and Economopoulos ${ }^{209}$ determine that meniscal allograft shrinkage is common following transplantation and the average amount of shrinkage is $7 \%$; however, nearly $32 \%$ of the grafts had $10 \%$ or more shrinkage. For Lee et al. ${ }^{210}$ gross morphologic alterations, as determined by width and thickness, were observed during the first postoperative year with a substantial shrinkage at the mid-body occurred progressively for 1 year in $16.1 \%$ of the cases, but had no association with the shortterm clinical outcomes.

Extrusion of the meniscus has been reported as a complication after meniscus transplantation. Previous reports showed extrusion after MAT was associated with development of osteoarthritis ${ }^{211}$. Ha et al. ${ }^{212}$ found that the extent of meniscal extrusion increased in the subgroup in which osteoarthritis had progressed according to MRI evidence. Lee et al. ${ }^{213}$ assessed the incidence of graft extrusion on the sagittal plane on MRI and showed that more anterior allograft placement correlated with a greater degree of graft extrusion on the coronal plane. Graft extrusion after MAT may be affected by horn fixation, which differs between medial and lateral meniscus transplantation. The amount and incidence of graft extrusion were greater after medial than lateral MAT in both the coronal and sagittal planes. In the sagittal plane, graft extrusion was greater and more frequent on the anterior than the posterior horn in both medial and lateral MAT. However, graft extrusion was not correlated with early clinical outcomes after both medial and lateral MAT214. More anterior allograft placement correlated with a greater degree of graft extrusion on the coronal plane. Noyes et al. ${ }^{215}$ determined the incidence and clinical significance of postoperative meniscus transplant extrusion. A systematic search was performed and three measurements were used to assess extrusion: absolute millimeters of extrusion $(0-8.8 \mathrm{~mm})$, relative percentage of extrusion $(0$ $100 \%)$, and the percentage of transplants that were extruded (0-100\%). Relationships between transplant extrusion and clinical rating scales, joint space narrowing on standing radiographs, and osteoarthritis progression were inconclusive. Non-anatomic placement of lateral meniscus transplants and suture fixation of medial and lateral transplants were associated with greater extrusion in two studies. A postoperative MRI showing more than 3-mm extrusion occurring in some studies suggested technique and/or implant sizing problems that required correction.

For Faivre et al. ${ }^{216}$ arthroscopic MAT with trans-tibial bone fixation ensures better mid-term functional outcomes and limits allograft extrusion. Verdonk et al. ${ }^{217}$ established that the transplanted lateral meniscus, without bone block fixation but with firm fixation of the horns to the original entheses, extrudes in the lateral direction significantly more than the normal meniscus. Open surgery is associated with less meniscal extrusion. Yoon et al. ${ }^{218}$ found more graft extrusion in the medial group on MRI, but Koh et al. ${ }^{219}$ observed that transplanted lateral menisci extruded more significantly than transplanted medial menisci. However, the clinical outcome after MAT was not found to be adversely affected by extrusion of the allograft. A meniscus that extrudes early remains extruded and does not progressively worsen, whereas one that does not extrude early is unlikely to extrude within the first postoperative year 220 .

\section{Conclusion}

Our overview of treatment for meniscal tear shows some promising step forward in the understanding of the important role of the meniscus that have led to a move toward meniscal preservation. Therapies that successfully repair or replace the meniscus are therefore likely to prevent or delay osteoarthritis progression. Meniscal repair, whenever possible, must be the preferred option for patients with a meniscal lesion. The biomechanical properties of the native meniscus are not copied entirely by the scaffolds that exist today. Congruence, fixation, biocompatibility and potential infection will always remain as limitations for the users of allografts. As research in biological augmentation and tissue engineering continues to develop, we expect that conservative treatments and meniscal replacement will be more widely used in younger patients in the future. 


\section{Conflict of interests}

The Authors declare that they have no conflict of interests regarding the publication of this paper.

\section{References}

1. Kambic HE, Futani $\mathrm{H}, \mathrm{McDevitt} \mathrm{CA}$. Cell matrix changes and alpha-smooth muscle actin expresion in repair of the canine meniscus. Wound Repair Regen. 2000; 8:554-561.

2. Potenza A, Herte M. The synovial cavity as a "tissue culture in situ": Science or nonsense. J Hand Surg. 1982;7:196-199.

3. Veth R, Jansen H, Leenslang J, Pennings A. Experimental meniscal lesions reconstructed with a carbon fiber-polyurethane-poly (L-lactide) graft. Clin Orthop Relat Res. 1986;202:286293.

4. Englund M, Roos EM, Roos HP, Lohmander LS. Patient-relevant outcomes fourteen years after meniscectomy: influence of type of meniscal tear and size of resection. Rheumatology. 2001;40:631-639.

5. Forriol F, Longo UG, Hernández-Vaquero D, Monllau JC, Montserrat $F$, Valentí JR, Vaquero J, et al. The effects of previous meniscus and anterior cruciate ligament injuries in patients with total knee arthroplasty. Ortop Traumatol Rehabil. 2010;12:50-57.

6. Heatley FW. The meniscus, can it be repaired: An experimental study in rabbits. J Bone Joint Surg (Am). 1980;65A:397402.

7. Guisasola I, Vaquero J, Forriol F. Knee inmobilization on meniscal healing after suture. An experimental study in sheep. Clin Orthop. 2002;395:227-233.

8. Martinez de Albornoz P, Forriol F. The meniscal healing process. Muscles Ligaments Tendons J. 2012;2:10-18.

9. Forriol F. Growth factors in cartilage and meniscus repair. Injury. 2009;40(Suppl 3):S12-16.

10. Forriol F, Longo UG, Duart J, et al. VEGF, BMP-7, Matrigel (TM), hyaluronic acid, in vitro cultured chondrocytes and trephination for healing of the avascular portion of the meniscus. An experimental study in sheep. Curr Stem Cell Res Ther. 2014;10:69-76.

11. Crawford R, Walley G, Bridgman S, Maffulli N. Magnetic resonance imaging versus arthroscopy in the diagnosis of knee pathology, concentrating on meniscal lesions and ACL tears: a systematic review. Br Med Bull. 2007;84:5-23.

12. Forriol F, Ripalda P, Duart J, Esparza R, Gortazar AR. Meniscal repair possibilities using bone morphogenetic protein-7. Injury. 2014;45(Suppl 4):15-21.

13. Chambers S, Cooney A, Caplan N, Dowen D, Kader D. The accuracy of magnetic resonance imaging (MRI) in detecting meniscal pathology. J R Nav Med Serv. 2014;100:157-160.

14. Roßbach BP, Pietschmann MF, Gülecyüz MF, et al. Indications requiring preoperative magnetic resonance imaging before knee arthroscopy. Arch Med Sci. 2014;10:1147-1152.

15. Padulo J, Oliva F, Frizziero A, Maffulli N. Muscles, Ligaments and Tendons Journal. Basic principles and recommendations in clinical and field science research. MLTJ. 2013;3(4):250-252.

16. Giuliani JR, Burns TC, Svoboda SJ, Cameron KL, Owens BD Treatment of meniscal injuries in young athletes. J Knee Surg. 2011;24:93-100

17. Fetzer GB, Spindler KP, Amendola A, et al. Potential market for new meniscus repair strategies: evaluation of the MOON cohort. J Knee Surg. 2009; 22:180-186.

18. Maffulli N, Longo UG, Campi S, Denaro V. Open Access J Sports Med. 2010;1:45-54.

19. Beaufils $P$, Hulet $C$, Dhénain M, Nizard R, Nourissat G, Pujol $\mathrm{N}$. Clinical practice guidelines for the management of meniscal lesions and isolated lesions of the anterior cruciate ligament of the knee in adults. Orthop Traumatol Surg Res. 2009;95:437442.

20. Forriol F, Vaquero J. Las suturas meniscales. Rev Ortop Traumatol. 2002;46:271-279.

21. Casscells SW. The place of arthroscopy in the diagnosis and treatment of internal derangement of the knee: an analysis of 1000 cases. Clin Orthop Relat Res. 1980;151:135-142.

22. Herrlin $\mathrm{S}$, Hållander $\mathrm{M}$, Wange $\mathrm{P}$, Weidenhielm $\mathrm{L}$, Werner $\mathrm{S}$. Arthroscopic or conservative treatment of degenerative medial meniscal tears: a prospective randomised trial. Knee Surg Sports Traumatol Arthrosc. 2007;15:393-401.

23. Stärke C, Kopf S, Petersen W, Becker R. Meniscal repair. Arthroscopy. 2009;25:1033-1044.

24. Shelton WR, Dukes AD. Technical note. Meniscus replacement with bone anchors: A surgical technique. Arthroscopy. 1994;10:324-327.

25. D'Lima DD, Chen PC, Kessler O, Hoenecke HR, Colwell CW $\mathrm{Jr}$. Effect of meniscus replacement fixation technique on restoration of knee contact mechanics and stability. Mol Cell Biomech. 2011;8:123-134.

26. Thieman KM, Pozzi A, Ling HY, Lewis D. Comparison of contact mechanics of three meniscal repair techniques and partial meniscectomy in cadaveric dog stifles. Vet Surg. 2010;39: 355-362.

27. Noyes FR, Barber-Westin SD. Meniscus transplantation: indications, techniques, clinical outcomes. Instr Course Lect. 2005;54:341-353.

28. Stone KR. Current and future directions for meniscus repair and replacement. Clin Orthop Rel Res. 1999;367(Suppl):273280.

29. Warren RF. Meniscectomy and repair in the anterior cruciate ligament - deficient knee. Clin Orthop Rel Res. 1990;252:55-63.

30. DeHaven K, Lohrer W, Lovelock J. Long term results of open meniscal repair. Am J Sports Med. 1995;23:524-530.

31. LaPrade RF, Burnett QM, Veenstra MA, Hodgman CG. The prevalence of abnormal magnetic resonance imaging findings in asymptomatic knees. With correlation of magnetic resonance imaging to arthroscopic findings in symptomatic knees. Am J Sports Med. 1994;22:739-745.

32. Papalia R, Del Buono A, Osti L, Denaro V, Maffulli N. Meniscectomy as a risk factor for knee osteoarthritis: a systematic review. Br Med Bull. 2011;99:89-106.

33. Barrett GR, Richardson K, Ruff CG, Jones A. The effect of suture type on meniscus repair, a clinical analysis. Am J Knee Surg. 1997;10:2-9.

34. Beamer BS, Masoudi A, Walley KC, et al. Analysis of a new allinside versus inside-out technique for repairing radial meniscal tears. Arthroscopy. 2015;31:293-298.

35. Kesto WK, Esquivel AO, Markel DC. Shear force at failure and stiffness of all-inside meniscal repair devices. J Knee Surg. 2013;26:435-440.

36. Kocabey Y, Taser O, Nyland J, et al. Horizontal suture placement influences meniscal repair fixation strength. Knee Surg Sports Traumatol Arthrosc. 2013;21:615-619.

37. Herbort M, Siam S, Lenschow S, Petersen W, Zantop T. Strategies for repair of radial tears close to the meniscal rim biomechanical analysis with a cyclic loading protocol. Am J Sports Med. 2010;38:2281-2287.

38. Barber FA, Herbert MA, Bava ED, Drew OR. Biomechanical testing of suture-based meniscal repair devices containing ultrahigh-molecular-weight polyethylene suture: update 2011. Arthroscopy. 2012; 28:827-834.

39. Turman KA, Diduch DR. Meniscal repair: indications and techniques. J Knee Surg. 2008;21:154-162.

40. Burns TC, Giuliani JR, Svoboda SJ, Owens BD. Meniscus repair and transplantation techniques. J Knee Surg. 2011;24:167174. 
41. Choi JY, Chang EY, Cunha GM, Tafur M, Statum S, Chung CB. Posterior medial meniscus root ligament lesions: MRI classification and associated findings. AJR Am J Roentgenol. 2014;203:1286-1292.

42. Barber FA, Bava ED. Meniscal repair: the newest fixators. Sports Med Arthrosc. 2012;20:95-100.

43. Dervin G, Downing K, Keene G, McBride D. Failure strength of suture versus biodegradable arrow for meniscal repair: An in vitro study. Arthroscopy. 1997;13:296-300.

44. Albrecht-Olsen P, Kristensen G, Burgaard P, Joergensen $U$, Toerholm C. The arrow versus horizontal suture in arthroscopic meniscus repair: a prospective randomised study with arthroscopic evaluation. Knee Surg Sports Traumatol Arthrosc. 1997;7:268-273.

45. Anderson L, Watts $\mathrm{M}$, Shapter O, et al. Repair of radial tears and posterior horn detachments of the lateral meniscus: minimum 2-year follow-up. Arthroscopy. 2010;26:1625-1632.

46. lanotti S, Golberg MJ. Richmond JC. Subcutaneous migration of bioabsorbable meniscal arrows Am J Knee Surg. 2001;14: 122-124.

47. Rosso C, Müller S, Buckland DM, et al. All-inside meniscal repair devices compared with their matched inside-out vertical mattress suture repair: introducing 10,000 and 100,000 loading cycles. Am J Sports Med. 2014;42:2226-2233.

48. Barber FA, Herbert MA, Schroeder FA, Aziz-Jacobo J, Sutker MJ. Biomechanical testing of new meniscal repair techniques containing ultra high-molecular weight polyethylene suture. Arthroscopy. 2009;25:959-967.

49. Yasunaga T, Kimura M, Kikuchi S. Histologic change of the meniscus and cartilage tissue after meniscal suture. Clin Orthop Rel Res. 2001;387:232-240.

50. Lamprakis AA, Fortis AP, Kostopoulos V, Vlasis K. Biomechanical testing of a shape memory alloy suture in a meniscal suture model. Arthroscopy. 2009;25:632-638.

51. Buckland D, Sadoghi $P$, Wimmer MD, et al. Meta-analysis on biomechanical properties of meniscus repairs: are devices better than sutures? Knee Surg Sports Traumatol Arthrosc. 2015;23:83-89.

52. Abdelkafy A. Short- to mid-term results of arthroscopic meniscal repair of long vertical longitudinal tears using combined cruciate and horizontal suture techniques: a retrospective study. Eur J Orthop Surg Traumatol. 2015;25:367-374.

53. Becker R, Schroder M, Starke C, Urbach D, Nebelung W. Biomechanical investigations of different meniscal repair implants in comparison with horizontal sutures on human meniscus. Arthroscopy. 2001;17:439-444.

54. Walsh SP, Evans SL, O'Doherty DM, Barlow IW. Failure strengths of suture vs. biodegradable arrow and staple for meniscal repair: an in vitro study. Knee. 2001;8:151-156.

55. Brucker PU, Favre P, Puskas GJ, von Campe A, Meyer DC, Koch PP. Tensile and shear loading stability of all-inside meniscal repairs: an in vitro biomechanical evaluation. Am J Sports Med. 2010;38:1838-1844.

56. Dutton AQ, Choong PF, Goh JC-H, Lee EH, Hui JHP. Enhancement of meniscal repair in the avascular zone using mesenchymal stem cells in a porcine model. J Bone Joint Surg (Br). 2010;92-B:169-175.

57. Hatsushika D, Muneta T, Nakamura T, et al. Repetitive allogeneic intraarticular injections of synovial mesenchymal stem cells promote meniscus regeneration in a porcine massive meniscus defect model. Osteoarthritis Cartilage. 2014;22:941950.

58. Arnoczky S, Warren R. The microvasculature of the meniscus and its response to injury: An experimental study in the dog. Am J Sports Med. 1983;11:131-141.

59. Longo UG, Campi S, Romeo G, Spiezia F, Maffulli N, Denaro V. Biological strategies to enhance healing of the avascular area of the meniscus. Stem Cells Int. 2012; 2012:528359.
60. Van Trommel M, Simonian P, Potter H. Arthroscopic meniscal repair with fibrin clot of complete radial tears of the lateral meniscus in the avascular zone. Arthroscopy. 1998;14:360365.

61. Piontek T, Ciemniewska-Gorzela K, Szulc A, Słomczykowski M, Jakob R. All-arthroscopic technique of biological meniscal tear therapy with collagen matrix. Pol Orthop Traumatol. 2012;77:39-45.

62. Ra HJ, Ha JK, Jang HS, Kim JG. Traumatic posterior root tear of the medial meniscus in patients with severe medial instability of the knee. Knee Surg Sports Traumatol Arthrosc. 2015; 23:3121-3126.

63. Kamimura T, Kimura M. Repair of horizontal meniscal cleavage tears with exogenous fibrin clots. Knee Surg Sports Traumatol Arthrosc. 2011;19:1154-1157.

64. Gershuni DH, Skyhar MJ, Danzing LA, Camp J, Hargens AR, Akeson WH. Experimental models to promote healing of tears in the avascular segment of the canine knee menisci. J Bone Joint Surg (Am). 1989;71-A:1363-1370.

65. Hashimoto J, Kurosaka M, Yoshiya S, Hirohata K. Meniscal repair using fibrin sealant and endotelial cell growth factor. An experimental study in dogs. Am J Sports Med. 1992;20:537541.

66. Koukoubis T, Glisson R, Feagin J, Seaber A, Vail T. Augmentation of meniscal repairs with cyanoacrylate glue. J Biomed Mater Res. 1995;29:715-720.

67. Tsai C, Liu T, Liu C, Lim A. Meniscal repair with autogenous periosteum and fibrin adhesive system. Chung Hua I Hsueh Tsa Chih (Taipei). 1992;49:170-176.

68. Jo $\mathrm{CH}$, Yoon KS, Lee JH, et al. Under-meniscal portal: an alternative portal for an easy access to the medial and lateral menisci. Knee Surg Sports Traumatol Arthrosc. 2009;17: 1344-1346.

69. Koga H, Engebretsen L, Brinchmann JE, Muneta T, Sekiya I. Mesenchymal stem cell-based therapy for cartilage repair: a review. Knee Surg Sports Traumatol Arthrosc. 2009;17:12891297.

70. Hori J, Deie M, Kobayashi T, Yasunaga Y, Kawamata S, Ochi M. Articular cartilage repair using an intra-articular magnet and synovium-derived cells. J Orthop Res. 2011;29:531-538.

71. Segawa $Y$, Muneta $T$, Makino H, et al. Mesenchymal stem cells derived from synovium, meniscus, anterior cruciate ligament, and articular chondrocytes share similar gene expression profiles. J Orthop Res. 2009; 27:435-441.

72. Ochi M, Uchio Y, Kawasaki K, Wakitani S, Iwasa J. Transplantation of cartilage-like tissue made by tissue engineering in the treatment of cartilage defects of the knee. J Bone Joint Surg (Br). 2002;84-B:571-578.

73. Esparza R, Gortazar AR, Forriol F. Cell study of the three areas of the meniscus: effect of growth factors in an experimental model in sheep. J Orthop Res. 2012;30:1647-1651.

74. Cisa J, Basora J, Madarnas P, Ghibely A, Navarro A. Meniscal repair by sinovial flap transfer: healing of the avascular zone in rabbits. Acta orthop scand. 1995;66:38-40.

75. Kobuna Y, Shirakura K, Niijima M. Meniscal repair using a flap of synovium. An experimental study in the dog. Am J Knee Surg. 1995;8:52-55.

76. Shirakura K, Niijima M, Kobuna Y, Kizuki S. Free synovium promotes meniscal healing. Synovium, muscle and synthetic mesh compared in dogs. Acta orthop scand. 1997;68:51-54.

77. Ikeuchi H. Arthroscopic treatment of the discoid lateral meniscus. Technique and long-term results. Clin Orthop Relat Res. 1982;167:19-28.

78. DeHaven KE. Decision-making factors in the treatment of meniscus lesions. Clin Orthop Rel Res. 1990;252:49-54.

79. Henning CE, Lynch MA, Yearout KM, Vequist SW, Stallbaumer RJ, Decker KA. Arthroscopic meniscal repair using an exogenous fibrin clot. Clin Orthop Rel Res. 1990; 252:64-72. 
80. DeHaven K, Black K, Griffiths H. Open meniscus repair, technique and two to nine year results. Am J Sports Med. 1989;17: 788-795.

81. Scott GA, Jolly BL, Henning CE. Combined posterior incision and arthroscopic intra-articular repair of the meniscus. J Bone Joint Surg (Am). 1986; 68A:847-861.

82. Shelbourne KD, Dersam MD. Comparison of partial meniscectomy versus meniscus repair for bucket-handle lateral meniscus tears in ACL reconstruccted knees. Arthroscopy. 2004; 20:581-585.

83. Greis PE, Holmstrom MC, Bardana DD, Burks RT. Meniscal injury: II. Management. J Am Acad Orthop Surg. 2002;10:177187.

84. Henning CE. Arthroscopic repair of meniscus tears. Orthopaedics. 1983;6:1130-1132.

85. Tengrootenhuysen M, Meermans G, Pittoors K, van Riet R, Victor J. Long-term outcome after meniscal repair. Knee Surg Sports Traumatol Arthrosc. 2011;19:236-241.

86. Stone K, Rodkey W, Webber R, McKinney L, Steadman J. Future directions. Collagen-Based Prostheses for meniscal regeneration. Clin Orthop Rel Res. 1990;252:129-135.

87. Cooper DE, Arnoczky SP, Warren RF. Arthroscopic meniscal repair. Clin Sports Med. 1990; 9:589-607.

88. Rosemberg J, Scott S, Paulos L. Arthroscopic surgery; repair of peripheral detachment of the meniscus. Contemp Orthop. 1985;10:43-50.

89. Cannon WD, Vittori JM. The incidence of healing in arthroscopic meniscal repairs in anterior cruciate ligament-reconstructed knees versus stable knees. Am J Sports Med. 1992;20:176-181.

90. Nepple JJ, Dunn WR, Wright RW. Meniscal repair outcomes at greater than five years: a systematic literature review and meta-analysis. J Bone Joint Surg (Am). 2012;94-A:22222227.

91. Rubman M, Noyes F, Barber-Westin S. Arthroscopic repair of meniscal tears that extend into the avascular zone. A review of 198 single and complex tears. Am J Sports Med. 1998;26:8795.

92. Eggli S, Wegmüller H, Kosina J, Huckell C, Jakob R. Long term results of arthroscopic meniscal repair: An analysis of isolated tears. Am J Sports Med. 1995;23:715-720.

93. Narazaki S, Furumatsu T, Tanaka T, et al. Postoperative change in the length and extrusion of the medial meniscus after anterior cruciate ligament reconstruction. Int Orthop. 2015.

94. Shybut TB, Vega CE, Haddad J, et al. Effect of Lateral Meniscal Root Tear on the Stability of the Anterior Cruciate Ligament-Deficient Knee. Am J Sports Med. 2015;43:905-911.

95. Martínez de Albornoz Torrente P, Forriol F. Modificación del liquido sinovial en diferentes afecciones articulares de la rodilla. Rev Esp Cir Ortop Traumatol. 2012;56:140-148.

96. de Girolamo L, Galliera E, Volpi P, et al. Why menisci show higher healing rate when repaired during $\mathrm{ACL}$ reconstruction? Growth factors release can be the explanation. Knee Surg Sports Traumatol Arthrosc. 2015;23:90-96.

97. Osawa A, Harner CD, Gharaibeh B, et al. The use of blood vessel-derived stem cells for meniscal regeneration and repair. Med Sci Sports Exerc. 2013;45:813-823.

98. Nicholas SJ, Golant A, Schachter AK, Lee SJ. A new surgical technique for arthroscopic repair of the meniscus root tear. Knee Surg Sports Traumatol Arthrosc. 2009;17:1433-1436.

99. Petersen W, Forkel P, Feucht MJ, Zantop T, Imhoff AB, Brucker PU. Posterior root tear of the medial and lateral meniscus. Arch Orthop Trauma Surg. 2014;134:237-255.

100. Osti L, Del Buono A, Maffulli N. Anterior Medial Meniscal Root Tears: A Novel Arthroscopic All Inside Repair. Transl Med UniSa. 2014;12:41-46.

101. Mariani PP. Posterior horn instability of the medial meniscus a sign of posterior meniscotibial ligament insufficiency. Knee
Surg Sports Traumatol Arthrosc. 2011;19:1148-1153.

102. Papalia R, Vasta S, Franceschi F, D'Adamio S, Maffulli N, Denaro V. Meniscal root tears: from basic science to ultimate surgery. Br Med Bull. 2013;106:91-115.

103. Cerminara AJ, LaPrade CM, Smith SD, Ellman MB, Wijdicks $\mathrm{CA}$, LaPrade RF. Biomechanical evaluation of a transtibial pull-out meniscal root repair: challenging the bungee effect. Am J Sports Med. 2014;42:2988-2995.

104. Espejo-Baena A, Figueroa-Mata A, Serrano-Fernández J, de la Torre-Solís F. All-inside suture technique using anterior portals in posterior horn tears of lateral meniscus. Arthroscopy. 2008;24:369.

105. Lee DW, Jang SH, Ha JK, Kim JG, Ahn JH. Meniscus root refixation technique using a modified Mason-Allen stitch. Knee Surg Sports Traumatol Arthrosc. 2013;21:654-657.

106. Röpke EF, Kopf S, Drange S, Becker R, Lohmann CH, Stärke C. Biomechanical evaluation of meniscal root repair: a porcine study. Knee Surg Sports Traumatol Arthrosc. 2015;23:45-50.

107. Rosslenbroich SB, Borgmann J, Herbort M, Raschke MJ, Petersen W, Zantop T. Root tear of the meniscus: biomechanical evaluation of an arthroscopic refixation technique. Arch Orthop Trauma Surg. 2013;133:111-115.

108. Sanz-Pérez M, García-Germán D, Ruiz-Díaz J, Navas-Pernía I, Campo-Loarte J. Localización de la arteria poplítea y su relación con el riesgo vascular en la sutura del cuerno posterior del menisco externo. Rev Esp Cir Ortop Traumatol. 2014; 59:165-171.

109. Sobhy MH, AbouElsoud MM, Kamel EM, Desouki AM. Neurovascular safety and clinical outcome of outside-in repair of tears of the posterior horn of the medial meniscus. Arthroscopy. 2010;26:1648-1654.

110. Baena AE, Castilla BM, Fernandez JS, de Rota Conde AF, Reina $A E$, Rubio FE. Inside-out medial meniscus suture: an analysis of the risk of injury to the popliteal neurovascular bundle. Arthroscopy. 2011;27:516-521.

111. Cohen SB, Boyd L, Miller MD. Vascular risk associated with meniscal repair using Rapidloc versus FasT-Fix: comparison of two all-inside meniscal devices. J Knee Surg. 2007;20:235240.

112. Malachowski KA, Weismeier K, Wirth CJ, Kohn D. Meniscus transplantation and anterior cruciate ligament replacement results 2-4 years postoperative. Sportverletz Sportschaden. 1990;4:73-78.

113. Keene GCR, Paterson RS, Teague DC. Advances in arthroscopic surgery. Clin Orthop Rel Res. 1987;224:64-70.

114. Toyonaga $\mathrm{P}$, Uezaki N, Chikama $\mathrm{H}$. Sustitute meniscus of teflon-net for the knee joint of dogs. Clin Orthop Rel Res. 1983; 179:291-297.

115. De Groot JH, de Vrijer R, Pennings AJ, Klompmaker J, Veth $\mathrm{RP}$, Jansen HW. Use of porous polyurethanes for meniscal reconstruction and meniscal prostheses. Biomaterials. 1996;17: 163-173.

116. Tienen TG, Heijkants RG, de Groot JH, et al. Replacement of the knee meniscus by a porous polymer implant: a study in dogs. Am J Sports Med. 2006;34:64-71.

117. Gastel JA, Muirhead WR, Lifrak JT, Fadale PD, Hulstyn MJ, Labrador DP. Meniscal tissue regeneration using a collagenous biomaterial derived from porcine small intestine submucosa. Arthroscopy. 2001;17:151-159.

118. Klompmaker J, Veth RP, Jansen HW, et al. Meniscal repair by fibrocartilage in the dog: characterization of the repair tissue and the role of vascularity. Biomaterials. 1996;17:1685-1691.

119. Rodkey WG, DeHaven KE, Montgomery WH 3rd, et al. Comparison of the collagen meniscus implant with partial meniscectomy. A prospective randomized trial. J Bone Joint Surg (Am). 2008;90-A:1413-1426.

120. Myers KR, Sgaglione NA, Goodwillie AD. Meniscal scaffolds. J Knee Surg. 2014;27:435-442. 
121. Stollsteimer GT, Shelton WR, Dukes A, Bomboy AL. Meniscal allograft transplantation: a 1- to 5-year follow-up of 22 patients. Arthroscopy. 2000;16:343-347.

122. Graf KW Jr, Sekiya JK, Wojtys EM. Long-term results after combined medial meniscal allograft transplantation and anterior cruciate ligament reconstruction: minimum 8.5-year followup study. Arthroscopy. 2004; 20:129-140.

123. Hommen JP, Applegate GR, Del Pizzo W. Meniscus allograft transplantation: ten-year results of cryopreserved allografts. Arthroscopy. 2007;23:388-393.

124. Saltzman BM, Bajaj S, Salata M, Daley EL, Strauss E, Verma $\mathrm{N}$, Cole BJ. Prospective long-term evaluation of meniscal allograft transplantation procedure: a minimum of 7-year followup. J Knee Surg. 2012;25:165-175.

125. Zhang H, Liu X, Wei Y, Hong L, Geng XS, Wang XS, Zhang J, Cheng KB, Feng $\mathrm{H}$. Meniscal allograft transplantation in isolated and combined surgery. Knee Surg Sports Traumatol Arthrosc. 2012;20:281-289.

126. Marcacci M, Marcheggiani Muccioli GM, Grassi A, Ricci M, Tsapralis K, Nanni G, Bonanzinga T, Zaffagnini S. Arthroscopic meniscus allograft transplantation in male professional soccer players: a 36-month follow-up study. Am J Sports Med. 2014;42:382-388.

127. Vundelinckx B, Vanlauwe J, Bellemans J. Long-term subjective, clinical, and radiographic outcome evaluation of meniscal allograft transplantation in the knee. Am J Sports Med. 2014;42:1592-1599.

128. Kazi HA, Abdel-Rahman W, Brady PA, Cameron JC. Meniscal allograft with or without osteotomy: a 15-year follow-up study. Knee Surg Sports Traumatol Arthrosc. 2015;23:303-309.

129. Getgood A, Gelber J, Gortz S, De Young A, Bugbee W. Combined osteochondral allograft and meniscal allograft transplantation: a survivorship analysis. Knee Surg Sports Traumatol Arthrosc. 2015;23:946-953.

130. Stone KR, Adelson WS, Pelsis JR, Walgenbach AW, Turek TJ. Long-term survival of concurrent meniscus allograft transplantation and repair of the articular cartilage: a prospective two- to 12-year follow-up report. J Bone Joint Surg (Br). 2010; 92-B:941-948.

131. Mauck RL, Burdick JA. From repair to regeneration: biomaterials to reprogram the meniscus wound microenvironment. Ann Biomed Eng. 2015;43:529-542.

132. Steadman JR, Rodkey WG. Tissue-engineered collagen meniscus implants: 5- to 6-year feasibility study results. Arthroscopy. 2005;21:515-525.

133. Rodkey WG, Steadman JR, Li S-T. A clinical study of Collagen Meniscus Implants to restore the injured meniscus. Clin Orthop Rel Res. 1999;367(Suppl):281-292.

134. Stone K, Rodkey W, Webber R, McKinney L, Steadman J. Meniscal regeneration with copolymeric collagen scaffolds. In vitro and in vivo studies evaluated clinically, histologically and biochemically. Am J Sports Med. 1992;20:104-111.

135. Stone KR, Steadman JR, Rodkey WG, Li ST. Regeneration of meniscal cartilage with use of a collagen scaffold. Analysis of preliminary data. J Bone Joint Surg (Am). 1997;79-A:1770-1777.

136. Zaffagnini S, Grassi A, Marcheggiani Muccioli GM, et al. MRI evaluation of a collagen meniscus implant: a systematic review. Knee Surg Sports Traumatol Arthrosc. 2015;23:32283237.

137. Monllau JC, Gelber PE, Abat F, et al. Outcome after partial medial meniscus substitution with the collagen meniscal implant at minimum of 10 years' follow-up. Arthroscopy. 2011;27:933943.

138. Verdonk R, Verdonk P, Huysse W, Forsyth R, Heinrichs EL. Tissue ingrowth after implantation of a novel, biodegradable polyurethane scaffold for treatment of partial meniscal lesions. Am J Sports Med. 2011;39:774-782.

139. Spencer SJ, Saithna A, Carmont MR, Dhillon MS, Thompson
$\mathrm{P}$, Spalding T. Meniscal scaffolds: early experience and review of the literature. Knee. 2012;19:760-765.

140. Gelber PE, Gonzalez G, Lloreta JL, Reina F, Caceres E, Monllau JC. Freezing causes changes in the meniscus collagen net: a new ultrastructural meniscus disarray scale. Knee Surg Sports Traumatol Arthrosc. 2008;16:353-359.

141. Verdonk PCM, Forsyth RG, Wang J, et al. Characterisation of human knee meniscus cell phenotype. Osteoarthritis Cartilage. 2005;13:548-560.

142. Verdonk R. Alternative treatment for meniscal injuries. J Bone Joint Surg (Br). 1997;79-B:866-873.

143. Wirth CJ, Peters G, Milachowski KA, Weismeier KG, Kohn D. Long-term results of meniscal allograft transplantation. Am J Sports Med. 2002;30:174-181.

144. Wada Y. Meniscal transplantation using fresh and cryopreserved allografts. An experimental study in the genetically defined rat. Nippon Seikeigeka Gakkai Zasshi. 1993;67:677-683.

145. Jackson DW, Whelan J, Simon TM. Cell survival after transplantation of fresh meniscal allografts. DNA probe analysis in a goat model. Am J Sports Med. 1993;21:540-555.

146. Ryu RK, Dunbar VWH, Morse GG. Meniscal allograft replacement: A 1-year to 6 year experience. Arthroscopy. 2002;18 :989-994.

147. Cameron JC, Saha S. Meniscal allograft transplantation for unicompartimental artritis of the knee. Clin Orthop Rel Res. 1997;337:164-171.

148. Stone KR, Walgenbach AW, Turek TJ, Freyer A, Hill MD. Meniscus allograft survival in patients with moderate to severe unicompartmental arthritis: a 2- to 7-year follow-up. Arthroscopy. 2006;22:469-478.

149. Pasa L, Pokorný V, Kalandra S, Melichar I, Bilik A. Transplantace hluboce mrazenych meniskú. Acta Chir Orthop Traumatol Cech. 2008;75:40-47.

150. Kuhn J, Wojtys E. Allograft meniscus transplantation. Clin Sports Med. 1996;15:537-546.

151. Rodeo SA, Seneviratne A, Suzuki K, Felker K, Wickiewicz TL, Warren RF. Histological analysis of human meniscal allografts. A preliminary report. J Bone Joint Surg (Am). 2000;82A:1071-1082.

152. Samitier G, Alentorn-Geli E, Taylor DC, et al. Meniscal allograft transplantation. Part 1: systematic review of graft biology, graft shrinkage, graft extrusion, graft sizing, and graft fixation. Knee Surg Sports Traumatol Arthrosc. 2015;23:310-322.

153. Fabbriciani C, Lucania L, Milano G, Panni AS, Evangelisti M. Meniscal allografts: cryopreservation vs deep-frozen technique. An experimental study in goats. Knee Surg Sports Traumatol Arthrosc. 1997;5:124-134.

154. Matava MJ. Meniscal allograft transplantation: a systematic review. Clin Orthop Rel Res. 2007:455:142-157.

155. Wajsfisz A, Meyer A, Makridis KG, Hardy P. A new arthroscopic technique for lateral meniscal allograft transplantation: cadaver feasibility study. Orthop Traumatol Surg Res. 2013:99:299-304.

156. Noyes FR, Barber-Westin SD, Rankin M. Meniscal transplantation in symtomatic patients less than fifty years old. J Bone Joint Surg (Am). 2004;86-A:1392-1404.

157. Noyes FR, Barber-Westin SD. A systematic review of the incidence and clinical significance of postoperative meniscus transplant extrusion. Knee Surg Sports Traumatol Arthrosc. 2015;23:290-302.

158. Lewis PB, Williams JM, Hallab N, Virdi A, Yanke A, Cole BJ. Multiple freeze-thaw cycled meniscal allograft tissue: $A$ biomechanical, biochemical, and histologic analysis. J Orthop Res. 2008:26:49-55.

159. Bursac P, York A, Kuznia P, Brown LM, Arnoczky SP. Influence of donor age on the biomechanical and biochemical properties of human meniscal allografts. Am J Sports Med. 2009;37:884-889. 
160. Gelber PE, Gonzalez G, Torres R, Garcia Giralt N, Caceres E, Monllau JC. Cryopreservation does not alter the ultrastructure of the meniscus. Knee Surg Sports Traumatol Arthrosc. 2009;17:639-644.

161. Gelber PE, Isart A, Erquicia JI, Pelfort X, Tey-Pons M, Monllau JC. Partial meniscus substitution with a polyurethane scaffold does not improve outcome after an open-wedge high tibial osteotomy. Knee Surg Sports Traumatol Arthrosc. 2015;23:334339.

162. Villalba R, Peña J, Navarro P, et al. Cryopreservation increases apoptosis in human menisci. Knee Surg Sports Traumatol Arthrosc. 2012;20:298-303.

163. Pollard ME, Kang Q, Berg E. Radiographic sizing for meniscal transplantation. Arthroscopy. 1995;11:684-687.

164. Jang KM, Wang $\mathrm{JH}$. Lateral meniscus allograft transplantation using a single-incision technique. Knee Surg Sports Traumatol Arthrosc. 2015; 23:258-263.

165. Dienst M, Greis PE, Ellis BJ, Bachus KN, Burks RT. Effect of lateral meniscal allograft sizing on contact mechanics of the lateral tibial plateau: an experimental study in human cadaveric knee joints. Am J Sports Med. 2007;35:34-42.

166. Prodromos CC, Joyce BT, Keller BL, Murphy BJ, Shi K. Magnetic resonance imaging measurement of the contralateral normal meniscus is a more accurate method of determining meniscal allograft size than radiographic measurement of the recipient tibial plateau. Arthroscopy. 2007; 23:1174-1179.

167. Haut TL, Hull ML, Howell SM. Use of roentgenography and magnetic resonance imaging to predict meniscal geometry determined with a three-dimensional coordinate digitizing system. J Orthop Res. 2000;18:228-237.

168. Mickiewicz P, Binkowski M, Bursig H, Wróbel Z. X-ray microtomography-based measurements of meniscal allografts. Orthop Traumatol Surg Res. 2015;101:319-324.

169. Newman A, Daniels A, Burks R. Principles and Decision making in meniscal surgery. Arthroscopy. 1993;9:33-51.

170. Sommerlath K, Gillquist J. The effect of a meniscal prosthesis on knee biomechanics and cartilage. An experimental study in rabbits. Am J Sports Med. 1992;20:73-81.

171. Goertzen D, Gillquist J, Messner K. Tensile strength of the tibial meniscal attachements in the rabbit. J Biomed Mater Res. 1996; 30:125-128.

172. Paletta GA, Manning T, Snell E, Parker R, Bergfeld J. The effect of allograft meniscal replacement on intraarticular contact area and pressures in the human knee. A biomechanical study. Am J Sports Med. 1997;25:692-698.

173. Stone KR, Rosenberg T. Surgical Technique of meniscal replacement. Arthroscopy. 1993;9:234-237.

174. Rodeo SA. Meniscal allografts. Where do we stand? Am J Sports Med. 2001;29:246-259.

175. Donahue TLH, Hull ML, Rashid MM, Jacobs CR. How the stiffness of meniscal attachements and meniscal material properties affect tibio-femoral contact pressure computed using a validated finite element model of the human knee. J Biomech. 2003;36:19-34.

176. González-Lucena G, Gelber PE, Pelfort X, Tey M, Monllau JC. Meniscal allograft transplantation without bone blocks: a 5- to 8year follow-up of 33 patients. Arthroscopy. 2010;26:1633-1640.

177. Yoldas EA, Sekiya JK, Irrgang JJ, Fu FH, Harner CD. Arthroscopically assisted meniscal allograft transplantation with and without combined anterior cruciate ligament reconstruction Knee Surg Sports Traumatol Arthrosc. 2003;11:173-182.

178. Abat F, Gelber PE, Erquicia JI, Tey M, Gonzalez-Lucena G, Monllau JC. Prospective comparative study between two different fixation techniques in meniscal allograft transplantation. Knee Surg Sports Traumatol Arthrosc. 2013;21: 1516- 1522.

179. Wang $\mathrm{H}$, Chen T, Gee AO, et al. Altered regional loading patterns on articular cartilage following meniscectomy are not ful- ly restored by autograft meniscal transplantation. Osteoarthritis Cartilage. 2015;23:462-468.

180. Edwards D, Whittle S, Nissen M, Cohen B, Oakeshott R, Keene G. Radiographic changes in the knee after meniscal transplantation. An experimental study in a sheep model. Am J Sports Med. 1996;24:222-226.

181. Mora G, Alvarez E, Ripalda P, Forriol F. Articular cartilage degeneration after frozen meniscus and Achilles tendon allograft transplantation: experimental study in sheep. Arthroscopy. 2003;19:833-841.

182. Szomor ZL, Martin TE, Bonar F, Murrel GAC. The protective effects of meniscal transplantation on cartilage. An experimental study in sheep. J Bone Joint Surg (Am). 2000;82-A:80-88.

183. McNickle AG, Wang VM, Shewman EF, Cole BJ, Williams JM Performance of a sterile meniscal allograft in an ovine model. Clin Orthop Rel Res. 2009;467:1868-1876.

184. Rijk PC, Tigchelaar-Gutter W, Bernoski FP, Van Noorden CJ. Functional changes in articular cartilage after meniscal allograft transplantation: a quantitative histochemical evaluation in rabbits. Arthroscopy. 2006;22:152-158.

185. Aagaard H, Jörgensen U, Bojsen-Möller F. Reduced degenerative articular cartilage changes after meniscal allograft transplantation in sheep. Knee Surg Sports Traumatol Arthrosc. 1999;7:184-191.

186. Khoshgoftar M, Vrancken AC, van Tienen TG, Buma P, Janssen $D$, Verdonschot $N$. The sensitivity of cartilage contact pressures in the knee joint to the size and shape of an anatomically shaped meniscal implant. J Biomech. 2015;48:14271435.

187. Mascarenhas R, Yanke AB, Frank RM, Butty DC, Cole BJ. Meniscal allograft transplantation: preoperative assessment, surgical considerations, and clinical outcomes. J Knee Surg. 2014;27:443-458.

188. Efe T, Getgood A, Schofer MD, et al. The safety and short-term efficacy of a novel polyurethane meniscal scaffold for the treatment of segmental medial meniscus deficiency. Knee Surg Sports Traumatol Arthrosc. 2012;20:1822-1830.

189. Bulgheroni P, Bulgheroni E, Regazzola G, Mazzola C. Polyurethane scaffold for the treatment of partial meniscal tears. Clinical results with a minimum two-year follow-up. Joints. 2014;1:161-166.

190. Bouyarmane $\mathrm{H}$, Beaufils $\mathrm{P}$, Pujol N, et al. Polyurethane scaffold in lateral meniscus segmental defects: clinical outcomes at 24 months follow-up. Orthop Traumatol Surg Res. 2014; 100:153-157.

191. Baynat C, Andro C, Vincent JP, et al. Actifit synthetic meniscal substitute: experience with 18 patients in Brest, France. Orthop Traumatol Surg Res. 2014;100(8 Suppl):385-389.

192. Martín-Hernández C, Ranera-García M, Díaz-Martínez JV, et al. Resultados de un implante de poliuretano para el tratamiento del dolor persistente de rodilla tras meniscectomía parcial con un mínimo de dos años de seguimiento. Rev Esp Cir Ortop Traumatol. 2015;59:44-51.

193. Lee AS, Kang RW, Kroin E, Verma NN, Cole BJ. Allograft meniscus transplantation. Sports Med Arthrosc. 2012;20:106114.

194. Cole BJ, Dennis MG, Lee SJ, et al. Prospective evaluation of allograft meniscus transplantation: a minimum 2-year followup. Am J Sports Med. 2006;34:919-927.

195. Thijs $Y$, Witvrouw E, Evens B, Coorevits P, Almqvist F, Verdonk R. A prospective study on knee proprioception after meniscal allograft transplantation. Scand J Med Sci Sports. 2007;17:223-229.

196. van Arkel ERA, de Boer HH. Survival analysis of human meniscal transplantations. J Bone Joint Surg (Br). 2002;84B:227-231.

197. Rueff D, Nyland J, Kocabey Y, Chang HC, Caborn DN. Self-reported patient outcomes at a minimum of 5 years after allograft 
anterior cruciate ligament reconstruction with or without medial meniscus transplantation: an age-, sex-, and activity levelmatched comparison in patients aged approximately 50 years. Arthroscopy. 2006;22:1053-1062.

198. Spang JT, Dang AB, Mazzocca A, et al. The effect of medial meniscectomy and meniscal allograft transplantation on knee and anterior cruciate ligament biomechanics. Arthroscopy. 2010;26:192-201.

199. Harris JD, Cavo M, Brophy R, Siston R, Flanigan D. Biological knee reconstruction: a systematic review of combined meniscal allograft transplantation and cartilage repair or restoration. Arthroscopy. 2011;27:409-418.

200. Rue JP, Yanke AB, Busam ML, McNickle AG, Cole BJ. Prospective evaluation of concurrent meniscus transplantation and articular cartilage repair: minimum 2-year follow-up. Am J Sports Med. 2008:36:1770-1778.

201. Verdonk PC, Verstraete KL, Almqvist KF, et al. Meniscal allograft transplantation: long-term clinical results with radiological and magnetic resonance imaging correlations. Knee Surg Sports Traumatol Arthrosc. 2006;14:694-706.

202. El-Attar M, Dhollander A, Verdonk R, Almqvist KF, Verdonk P. Twenty-six years of meniscal allograft transplantation: is it still experimental? A meta-analysis of 44 trials. Knee Surg Sports Traumatol Arthrosc. 2011;19:147-157.

203. Smith NA, Parkinson B, Hutchinson CE, Costa ML, Spalding $\mathrm{T}$. Is meniscal allograft transplantation chondroprotective? A systematic review of radiological outcomes. Knee Surg Sports Traumatol Arthrosc. 2015

204. Lee SR, Kim JG, Nam SW. The tips and pitfalls of meniscus allograft transplantation. Knee Surg Relat Res. 2012;24:137145.

205. Meredith DS, Losina E, Mahomed NN, Wright J, Katz JN. Factors predicting functional and radiographic outcomes after arthroscopic partial meniscectomy: a review of the literature. Arthroscopy. 2005; 21:211-223.

206. Stone KR, Pelsis JR, Surrette ST, Walgenbach AW, Turek TJ. Meniscus transplantation in an active population with moderate to severe cartilage damage. Knee Surg Sports Traumatol Arthrosc. 2015;23:251-257.

207. Jung $\mathrm{YH}, \mathrm{Choi} \mathrm{NH}$, Victoroff BN. Arthroscopic stabilization of the lateral capsule of the knee in meniscal transplantation. Knee Surg Sports Traumatol Arthrosc. 2011;19:189-191.

208. Arnoczky S, Milachowsky K. Meniscal allografts: where do we stand? In: Ewing JW De. Articular cartilage and knee joint function. New York: Raven Press. 1990;129-136.
209. Carter T, Economopoulos KJ. Meniscal allograft shrinkageMRI evaluation. J Knee Surg. 2013;26:167-171.

210. Lee BS, Chung JW, Kim JM, Cho WJ, Kim KA, Bin SI. Morphologic changes in fresh-frozen meniscus allografts over 1 year: a prospective magnetic resonance imaging study on the width and thickness of transplants. Am J Sports Med. 2012;40:1384-1391.

211. Jung KA, Lee SC, Hwang SH. 'Suture-induced tear' after human meniscal allograft transplantation. Knee. 2010;17:88-91.

212. Ha JK, Jang HW, Jung JE, Cho SI, Kim JG. Clinical and radiologic outcomes after meniscus allograft transplantation at 1. year and 4-year follow-up. Arthroscopy. 2014;30:1424-1429.

213. Lee BK, Lee YS, Oh WS, Kim KH. Restoration of the anatomic position during a meniscal allograft transplantation using pre-existing landmarks. Arch Orthop Trauma Surg. 2015;135 393-399.

214. Lee YH, Caborn DN. A new technique for arthroscopic meniscus transplant using soft tissue fixation and anatomical meniscal root reinsertion. Knee Surg Sports Traumatol Arthrosc. 2012;20:904-908.

215. Noyes FR, Chen RC, Barber-Westin SD, Potter HG. Greater than 10-year results of red-white longitudinal meniscal repairs in patients 20 years of age or younger. Am J Sports Med. 2011;39:1008-1017.

216. Faivre B, Boisrenoult P, Lonjon G, Pujol N, Beaufils P. Lateral meniscus allograft transplantation: clinical and anatomic outcomes after arthroscopic implantation with tibial tunnels versus open implantation without tunnels. Orthop Traumatol Surg Res. 2014;100:297-302.

217. Verdonk P, Depaepe Y, Desmyter S, et al. Normal and transplanted lateral knee menisci: evaluation of extrusion using magnetic resonance imaging and ultrasound. Knee Surg Sports Traumatol Arthrosc. 2004;12:411-419.

218. Yoon JR, Jeong HI, Seo MJ, et al. The use of contralateral knee magnetic resonance imaging to predict meniscal size during meniscal allograft transplantation. Arthroscopy. 2014;30:1287-1293.

219. Koh YG, Moon HK, Kim YC, Park YS, Jo SB, Kwon SK. Comparison of medial and lateral meniscal transplantation with regard to extrusion of the allograft, and its correlation with clinica outcome. J Bone Joint Surg (Br). 2012;94:190-193.

220. Lee DH, Kim TH, Lee SH, Kim CW, Kim JM, Bin SI. Evaluation of meniscus allograft transplantation with serial magnetic resonance imaging during the first postoperative year: focus on graft extrusion. Arthroscopy. 2008;24:1115-1121. 